\title{
INEEL/EXT-98-00062
}

January 1998

\section{Mapping of Contamination at Savannah River Site FBWU By INEEL Trolley}

M. V. Carpenter

$$
\text { RECEIVED }
$$

MAR 131.998

R. J. Gehrke

R. G. Helmer

N. Josten 


\section{DISCLAIMER}

This report was prepared as an account of work sponsored by an agency of the United States Government. Neither the United States Government nor any agency thereot, nor any of their employees, makes any warranty, express or implied, or assumes any legal liability or responsibility for the accuracy. completeness, or usefulness of any information, apparatus, product or process disclosed, or represents that its use would not infringe privately owned nights. Reterences herein to any specific commercial product. process, or service by trade name, trademark, manutacturer, or otherwise, does not necessarily constitute or imply its endorsement, recommendation, or favoring by the United States Government or any agency thereof. The views and opinions of authors expressed herein do not necessarily state or reflect those of the United States Govemment or any agency thereof. 


\title{
Mapping of Contamination at Savannah River Site FBWU By INEEL Trolley
}

\author{
M. V. Carpenter \\ R. J. Gehrke \\ R. G. Helmer \\ N. Josten ${ }^{2}$
}

Published January 1998

Idaho National Engineering and Environmental Laboratory

Lockheed Martin Idaho Technologies Company

Idaho Falls, Idaho 83415

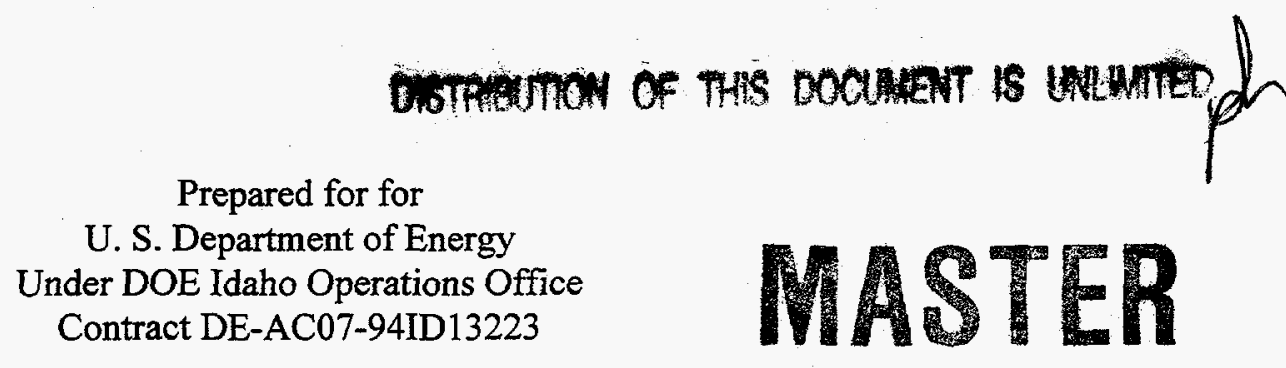

* Current address: Geosense, Idaho Falls, ID 83404 


\section{DISCLAIMER}

Portions of this document may be illegible electronic image products. Images are produced from the best available original document. 


\section{Executive Summary}

The Ford Building Waste Unit (FBWU) 643-11G is a Resource Conservation and Recovery Act/Comprehensive Environmental Response compensation and Liability Act RCRA/CERCLA designated site at the Savannah River site (SRS) in Aiken, South Carolina. Pre-Work Plan Characterization at the FBWU in May 1996 indicated that radiological contamination was present in surface and near surface soils and identified cesium- $137,{ }^{137} \mathrm{Cs}$, the unit specific contaminant, as being primarily in the top $15 \mathrm{~cm}$ of soil.

The Idaho National Engineering and Environmental Laboratory (INEEL) sent the dig-face trolley system to SRS where it demonstrated its capability over a $6.1-\mathrm{m}\left(20^{\prime}\right)$ x $9.6-\mathrm{m}\left(30^{\prime}\right)$ area to rapidly map the contamination on-line with its large area plastic scintillation detector. Also, an extended-range ( $10 \mathrm{keV}$ to $3 \mathrm{MeV}) \mathrm{Ge}$ detector was used at selected locations to identify and quantify the ${ }^{137} \mathrm{Cs}$ contamination. The coordinate locations of each measurement acquired in either the scanning or fixed position mode was obtained with a survey system based on radial encoders. Topography measurements were also made during measurements to permit correction of field of view and activity concentrations for changes in the ground to detector distance.

Calibration of the detectors was carried out by two methods: a) measurement of large-area planar sources of uniform and known activity concentration, and b) modeling of the detector-source geometry using the Monte Carlo electron/photon transport code CYLTRAN. For planar sources that fully covered the detector's field-of-view the measured and modeled efficiencies for the plastic scintillation detector agreed to $\pm 3 \%$ for the $662-\mathrm{keV} \gamma$ rays and for the Ge detector they agreed to $\pm 5 \%$ for the $661-\mathrm{keV} \gamma$ rays and to $\pm 25 \%$ for the $\mathrm{Ba} \mathrm{Kx}$ rays. Good agreement of the modeled efficiency with the measured efficiency provided verification that the model and code was able to accurately determine the efficiency for planar sources and therefore should be able to accurately determine the efficiency for volume sources whose dimensions, composition and density are known.

Determination of the activity concentration was most straight forward for the lowest area of contamination because in this location the horizontal extent of the contamination extends beyond the field of view of the plastic scintillation detector. However, even in this location the vertical distribution of the contamination could only be estimated. It was estimated to be uniform to 15 $\mathrm{cm}$ depth based on the barium $\mathrm{K}$-series $\mathrm{X}$-ray to gamma-ray $(\mathrm{Ba} \mathrm{K} \mathrm{x} / \gamma)$ ratio measured with the Ge detector at one location. Further, the background counting rate was not measured directly due to unmitigating circumstances but rather deduced from a correlation of counting rate with the activity concentration of the sample results. Although the correlation was very good, comparison of the natural background peaks with the peak area of the $662-\mathrm{keV} \gamma$ ray peak in the Ge spectrum implied that the deduced background counting rate may be too large. As a result, the deduced activity concentrations of the contamination from the plastic scintillation detector may be too low. This conclusion is supported by the Ge in situ measurements and sample results. 
Determination of the activity concentration was more difficult for the areas at and surrounding the highest areas of contamination. This was so because an accepted procedure or an algorithm to convert counting rate to activity concentration in locations of rapidly changing counting rate gradient over the field of view of the detector has not yet been developed or approved by the regulating agencies. These changes are due to a number of possibly rapidly varying parameters including the depth distribution and horizontal distribution of contamination, and to a lesser extent the lack of information on the density or moisture content of the soil. In spite of this lack of information, and the obvious fact that each of the three methods is measuring a different sample of the contamination, the activity concentrations measured by the different methods usually agree within a factor of two or three except over the highest levels of contamination.

From this demonstration several conclusions can be drawn: a) the color contour map of the contamination that was produced on line provides a valuable tool in locating all of the hot spots and the full extent of the contamination, b) contamination down to $\sim 1 \mathrm{pCi} / \mathrm{g}$ was readily located even with a scanning speed of $\sim 15 \mathrm{~cm} / \mathrm{s}, \mathrm{c}$ ) a cleanup level below $1 \mathrm{pCi} / \mathrm{g}$ is below detection levels for the plastic scintillation detector in the scanning mode of $\sim 15 \mathrm{~cm} / \mathrm{s}$, and d) quantification of the ${ }^{137} \mathrm{Cs}$ contamination with the plastic scintillation detector agreed with in situ Ge and sample results to within a factor of three even though each assay method was dealing with a different sample. Obviously, the classical in situ measurements made at one meter with unshielded scintillation or Ge detectors cover too large of a field of view to be of use when the contamination covers a rather small area, is rapidly changing over an area of a square meter, and detailed information on the extent and location of the contamination is needed.

In conclusion, it appears that the Dig Face Characterization System provides valuable qualitative maps and semiquantitative activity concentrations and has the potential to provide quantitative information to guide the cleanup operation. In this way the cleanup crew can make remediation decisions in a timely and efficient manner. When a fully developed protocol has been successfully tested, the need for sampling and off-site characterization could be reduced to only that required by regulation to verify final release criteria. Because in situ characterization results in $100 \%$ coverage of the site at a fraction of the cost of laboratory analyses, the Dig Face Characterization System will also significantly reduce the need for rework of a site that was believed to have been remediated, but remained with areas above the cleanup criteria. 


\section{Acknowledgments}

The authors wish to acknowledge the technical assistance of Ann Gibbs, Jonathan Kuhns, and Kenneth Hofstetter. In particular, we wish to thank Ken for making available to us equipment that made possible the collection of Ge spectra when our analyzer malfunctioned. We also wish to thank Sharon Fraley and the crew at the FBWU for their assistance. 


\section{Contents}

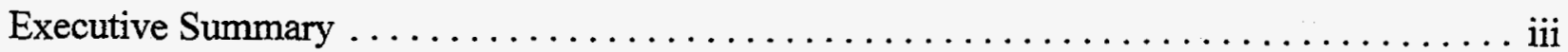

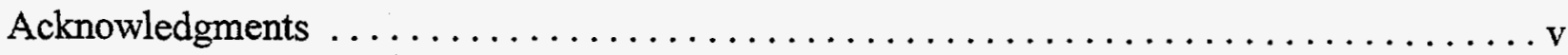

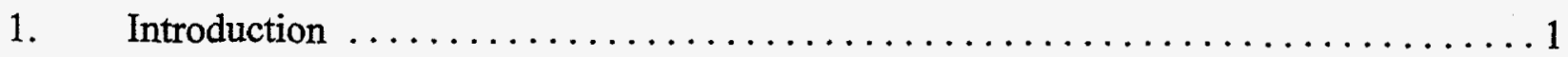

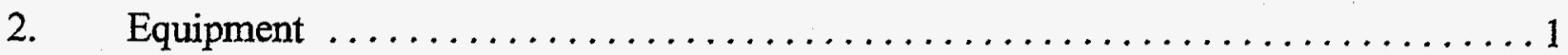

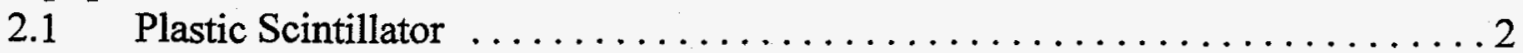

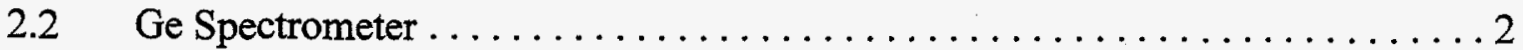

2.3 Magnetometer/Laser Rangefinder (MLR) $\ldots \ldots \ldots \ldots \ldots \ldots \ldots \ldots \ldots$

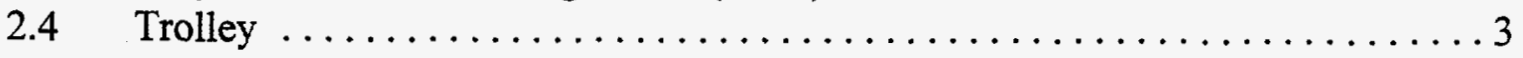

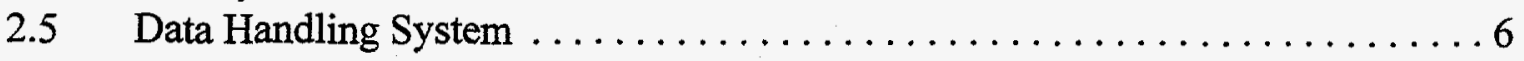

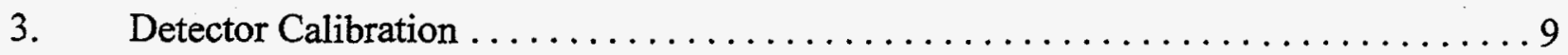

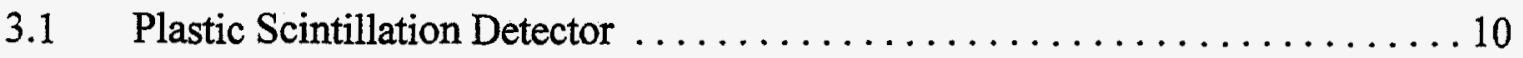

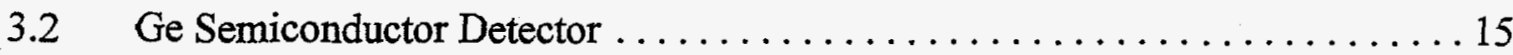

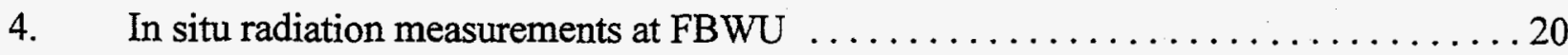

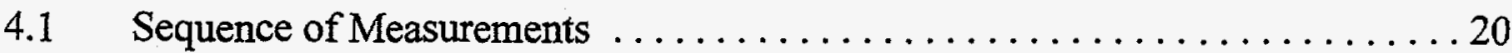

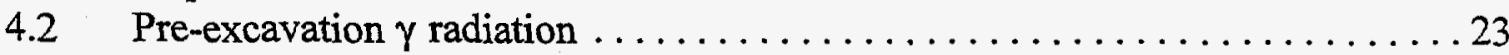

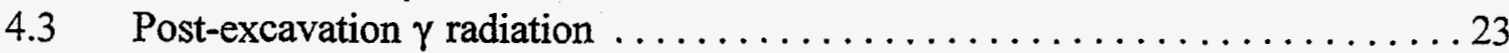

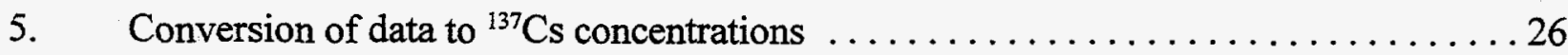

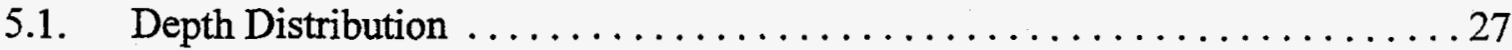

5.2 Background for the Plastic Scintillation Detector . . . . . . . . . . . . 2 27

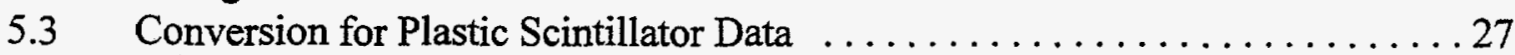

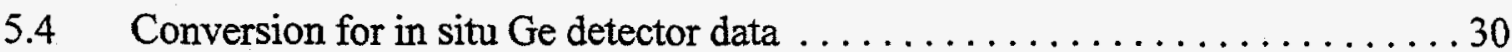

5.5 Comparison of ${ }^{137} \mathrm{Cs}$ Concentrations from Various Sets of Data . . . . . . . . 30

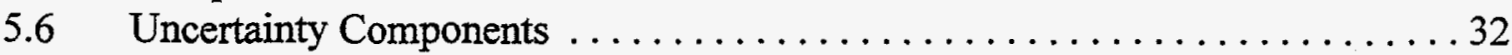

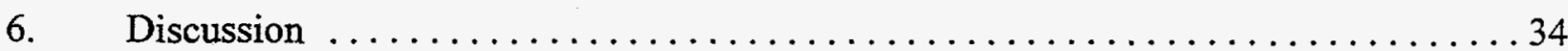

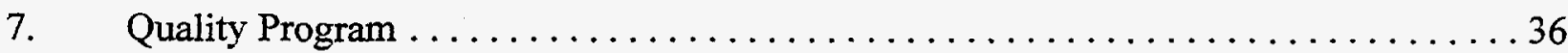

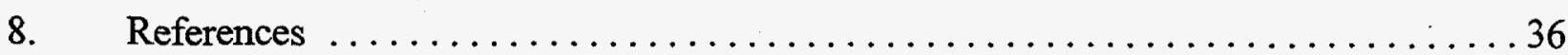

APPENDIX A SETTING THE LOWER-LEVEL DISCRIMINATOR OF A PLASTIC SCINTILLATION DETECTOR ........... A-1

APPENDIX B $\quad$ MONTE CARLO MODELING WITH CYLTRAN ............ B-1 


\section{Figures}

1. Photo of Ge spectrometer assembly consisting of a Ge detector in its collimator/shield, the Inspector portable multichannel analyzer, and the framework to attach to trolley. . . 4

2. Photo of the trolley-based sensor deployment system $\ldots \ldots \ldots \ldots \ldots \ldots \ldots \ldots$

3. Trolley system as set up on steel I-beam foundations at the FBWU. Also layout of

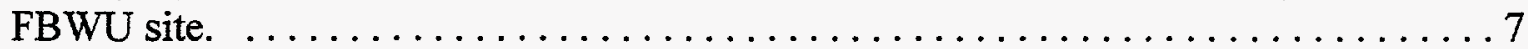

4. Coupling between the bridge and the main beam carriages $\ldots \ldots \ldots \ldots \ldots \ldots$

5. Plastic detector spatial resolution in full width at half maximum (FWHM) as determined with a point source at different source-to-detector distances $\ldots \ldots \ldots \ldots \ldots \ldots \ldots$

6. Plot of activity concentration from samples taken at locations indicated versus the counting rate of the plastic scintillation detector at the same location. The $\mathrm{x}$ intercept is one measure of the plastic scintillator background rate $\ldots \ldots \ldots \ldots \ldots \ldots$

7. Overview of area showing location of trolley $\ldots \ldots \ldots \ldots \ldots \ldots \ldots \ldots \ldots \ldots \ldots$

8. Overview of area showing some measured activity concentrations from samples and

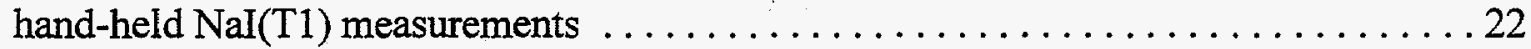

9. Color contour plot (map) of contaminated area with plastic scintillation detector - pre excavation. The sampling locations are shown as small circles superimposed on the contour plot with sample 1 corresponding with sample A1 and so forth with the remaining numbers. The Ge measurement points were at the same locations as the

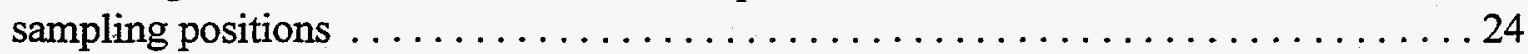

10. Color contour plot (map) of contaminated area with plastic scintillation detector-post

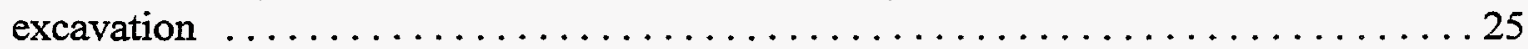

\section{Tables}

1. Plastic scintillation detector calibration for planar sources of $662-\mathrm{keV}$ photons. The statistical uncertainty for the modeled values are in parenthesis and represent one

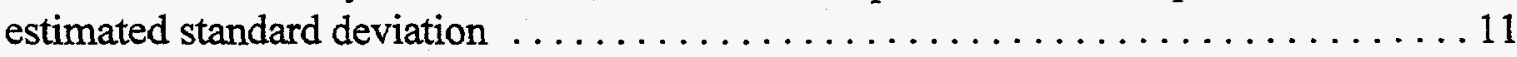


2. Plastic scintillation detector modeled calibration for disk sources of various diameters at various depths in soil with density of $1.5 \mathrm{~g} / \mathrm{cm}^{3}$ and deduced volume source calibrations

3. Ge Semiconductor detector calibration for planar sources $\ldots \ldots \ldots \ldots \ldots \ldots \ldots$

4. Ge semiconductor detector counts for $662-\mathrm{keV} \gamma$ ray from modeling for disk sources of various radii and depth in soil (density $1.5 \mathrm{~g} / \mathrm{cm}^{3}$ ) and deduced volume source values

5. Ge detectors counts in $\mathrm{Ba} \mathrm{K} \alpha$ peak from modeling $\ldots \ldots \ldots \ldots \ldots \ldots \ldots \ldots \ldots$

6. Modeled $\mathrm{K}_{\alpha} / \gamma$ peak area ratios for various ${ }^{137} \mathrm{Cs}$ source distributions $\ldots \ldots \ldots \ldots \ldots 19$

7. Count rates expected in plastic scintillation and Ge semiconductor detectors for volume sources of ${ }^{137} \mathrm{Cs}$ at $1.0 \mathrm{pCi} / \mathrm{g}$ and soil density of $1.5 \mathrm{~g} / \mathrm{cm}^{3} \ldots \ldots \ldots \ldots \ldots \ldots 20$

8. Summary of measurements with plastic scintillator mounted on INEEL trolley $\ldots \ldots 23$

9. $\quad{ }^{137} \mathrm{Cs}$ concentrations deduced from plastic scintillator data with background of 120 counts $/$ s ........................................... 29

10. ${ }^{137} \mathrm{Cs}$ concentrations deduced from the in situ Ge detector data $\ldots \ldots \ldots \ldots \ldots \ldots$

11. Comparisons of ${ }^{137} \mathrm{Cs}$ concentrations deduced $\ldots \ldots \ldots \ldots \ldots \ldots \ldots \ldots \ldots \ldots \ldots \ldots \ldots \ldots$ 


\title{
MAPPING OF CONTAMINATION AT
}

\author{
SAVANNAH RIVER SITE FBWU BY INEEL TROLLEY
}

\section{Introduction}

The Ford Building Waste Unit (FBWU) 643-11G is a (Resource Conservation and Recovery Act/Comprehensive Environmental Response Compensation and Liability Act) RCRA/CERCLA designated site at the Savannah River Site (SRS) in Aiken, South Carolina. Initial Site Characterization sampling at the FBWU 643-11G in May 1996 indicated that radiological contamination was present in surface and near surface soils ${ }^{1}$. This characterization identified cesium-137 $\left({ }^{137} \mathrm{Cs}\right)$ as the Unit Specific Contaminant and determined the approximate vertical extent of contamination [bulk of contamination in top $15 \mathrm{~cm}\left(6^{\prime \prime}\right)$ of soil]. A Removal Site Evaluation Report was prepared which identified a thallium activated sodium iodide [NaI(Tl)] scintillation detector as the method to be used to determine hot spots within the unit to be excavated ${ }^{2}$. The report also specified the use of the dig-face trolley system developed at the Idaho National Engineering and Environmental Laboratory (NEEL) for a technology demonstration. INEEL sent the dig-face trolley system to SRS where it supported the excavation in an area where the hand held-sensors recorded peak levels of radiation at the surface. Using the trolley and its associated remote data acquisition and control system, a plastic scintillation detector and a germanium $(\mathrm{Ge}) \gamma$-ray spectrometer were operated $\sim 15 \mathrm{~cm}$ above the ground surface of the contaminated area. The plastic scintillator was used to generate a map of the detector count rate over a $6.1-\mathrm{m},\left(20^{\prime}\right)$ x 9.6-m (30') area. Several Ge gamma $(\gamma)$-ray spectrometer measurements were made and samples were collected and analyzed at SRS laboratories along a diagonal line that began in the north east corner and passed through the area with the highest ${ }^{137} \mathrm{Cs}$ contamination. This report presents and analyzes these data and compares them in order to gain an understanding of the advantages and disadvantages of in situ data.

\section{Equipment}

The dig-face characterization system deployed at FBWU 643-11G has three fundamental components: a sensor subsystem, a deployment subsystem, and a data handling subsystem. The sensor system consists of a sensor suite matched to the conditions and radionuclide of interest 
during the retrieval operation. In the case of FBWU, the objective was to detect, map and quantify ${ }^{137} \mathrm{Cs}$ contamination in the soil. The deployment system delivers the sensors to locations where measurements are desired. The data handling system provides the capability to transmit data by radio frequency (RF) from sensors to a control station where they may be validated, analyzed and archived and combined to form a map of the contamination as a function of position.

\subsection{Plastic Scintillator}

A newly designed plastic scintillation detector system was developed for use at the FBWU $643-11 \mathrm{G}$ at SRS that consists of a $30 \times 30 \times 3.81 \mathrm{~cm}\left(12^{\prime \prime} \times 12^{\prime \prime} \times 1.5^{\prime \prime}\right)$ plastic scintillator with the pulses above a discriminator level stored in a scalar. The digital output is in RS232 communication protocol format for wireless communication to a Graphics Workstation. The detector and pulse processing circuitry are mounted as an integral assembly in a totally enclosed aluminum case. Shielding of $5-\mathrm{cm}\left(2^{\prime \prime}\right)$ thick lead bricks surrounded the plastic scintillator along its four sides, but no shielding was placed across the top of the detector. The front face of the scintillator was about $4.4 \mathrm{~cm}\left(1.7^{\prime \prime}\right)$ above the bottom of the lead brick shield which restricts the viewing angle of the soil that was $\sim 15 \mathrm{~cm}\left(6^{\prime \prime}\right)$ below the shield. The 10-cm (4") height of the lead bricks surrounding the sides of the plastic scintillator provides shielding even from radiation emitted from the walls of an excavation. This entire assembly with detector, electronics, shielding, and case weighs $\sim 105 \mathrm{~kg}$ (230 lbs). The electronic components, which can be removed from the shield and case, weigh about $11.8 \mathrm{~kg}$ (26 lbs). The field of view, as measured with large-area ${ }^{137} \mathrm{Cs}$ surface sources is approximately $120 \mathrm{~cm} \mathrm{x} 120 \mathrm{~cm}(4 \mathrm{ft} . \mathrm{x} 4 \mathrm{ft})$ at the height used.

Since any pulse above the lower-level discriminator registers a count, the plastic detector's large size allows it to quickly gather data as it scans the ground at a speed of $\sim 15 \mathrm{~cm} / \mathrm{s}$. Its poor energy resolution, however, means that only rarely can it differentiate one radionuclide from another. Because of this limitation, in situ Ge spectrometer measurements or grab samples are usually needed to determine the radionuclide composition of the contamination. From such measurements the dominant $\gamma$-ray emitting radionuclide contaminant at the FBWU was ${ }^{137} \mathrm{Cs}$. This protocol closely follows that used by other laboratories ${ }^{3}$. The laser range finder measured the sensor to ground distances for all measurements with the plastic scintillation detector in a separate map.

\subsection{Ge Spectrometer}

The Ge spectrometer assembly consists of a Ge semiconductor detector in a "Big Mac ${ }^{664}$ satellite all-attitude dewar (operates in any orientation) with a 3-day supply of liquid nitrogen $\left(\mathrm{LN}_{2}\right)$ coolant. The detector has a bismuth shield/collimator around it and the detector is recessed 7.9 $\mathrm{cm}$ from the front of the collimator. The shield/collimator wall thickness is 4.44-cm (1.75") and attenuates $661-\mathrm{keV}$ gamma radiation a factor of 20 . In its shield the detector has a field of view of $\sim 50-\mathrm{cm}$ diameter with the bottom of the collimator $15 \mathrm{~cm}\left(6^{\prime \prime}\right)$ above the ground. The shield 
itself weighs $\sim 31.8 \mathrm{~kg}(70 \mathrm{lbs})$. The Ge spectrometer pulse processing circuitry consists of a Canberra Industries portable multichannel analyzer (MCA) called the "Inspector" that is equipped with the INEEL designed dual-energy, low-power pulser5. The "Inspector" is held by two aluminum channel pieces that are mounted on one of two plates that support the Ge detector and the shield/collimator as shown in Figure 1. The spectral output of the "Inspector" is sent via a RS232 cable to a notebook personal computer (PC). This Ge detector assembly with detector/electronics, shield/collimator and support frame weighs $\sim 50 \mathrm{~kg}(110 \mathrm{lbs})$.

The Ge spectrometer consists of a single crystal of high-purity n-type Ge detector of $5.0 \mathrm{~cm}$ diameter and $2.0 \mathrm{~cm}$ thickness $\left(0.39 \mathrm{~cm}^{3}\right)$. Because of their smaller size, relative to scintillation detectors, Ge detectors are not usually used in a scanning mode, but rather as spectrometer at specific locations to identify and quantify. It has an energy resolution of $0.63-\mathrm{keV}$ FWHM at $122 \mathrm{keV}$ and $2.14 \mathrm{keV} \mathrm{FWHM}$ at $1332 \mathrm{keV}$.

The type of Ge detector used in the present study is a LEGE (low energy germanium) detector. This detector is equipped with a thin carbon fiber window that permits the measuring of photons ( $x$ and $\gamma$ rays) as low as $10 \mathrm{keV}$. This detector was an excellent choice since it permitted measurement of the barium $\mathrm{K} x$ ray emitted in the decay of ${ }^{137} \mathrm{Cs}$. The ratio of peak areas of these $\mathrm{x}$ rays to those of the $661-\mathrm{keV} \gamma$ rays can provide an estimate of the average depth distribution of the ${ }^{137} \mathrm{Cs}$ contamination.

\subsection{Magnetometer/Laser Rangefinder (MLR)}

The magnetometer/laser rangefinder is a combination sensor used to detect buried metallic debris and to map the topography of the dig-face. The laser rangefinder is mounted on the trolley and operates by measuring the travel time of laser pulses that are transmitted from it, reflected off the ground surface, and returned through the sensor lens. Topography measurements are made by scanning the MLR across the ground surface from a set height to conform with the radiation sensor height. The MLR is calibrated by setting a zero distance at a fixed calibration point with known elevation. This permits calculation of the sensor standoff distance above the ground, which effects the field of view and efficiency of the detector and therefore is a factor in analyzing the in situ radiation measurements. The magnetic sensor in the MLR is a high-speed fluxgate magnetic gradiometer mounted in the plastic stinger affixed to the bottom of the sensor housing. The magnetometer portion of the data were recorded during MLR scans, but were not evaluated.

\section{$2.4 \quad$ Trolley}

Figure 2 shows a picture of the trolley based sensor deployment system. The main components of the trolley are (a) the main beam or track ( $\mathrm{x}$-axis), (b) the bridge (y-axis), (c) the mast ( $\mathrm{z}$-axis), and (d) the motor drive system.

The main or $\mathrm{x}$-axis beam of the trolley has wheeled carriages or trucks that run on a simple track. These assemblies would allow the trolley to support excavations of unlimited length through use 


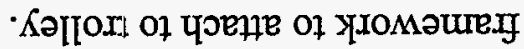

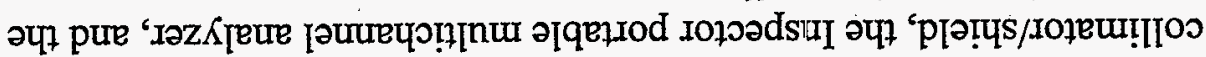

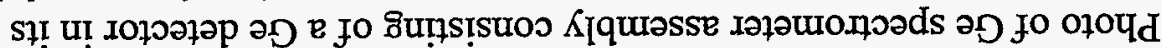

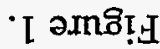

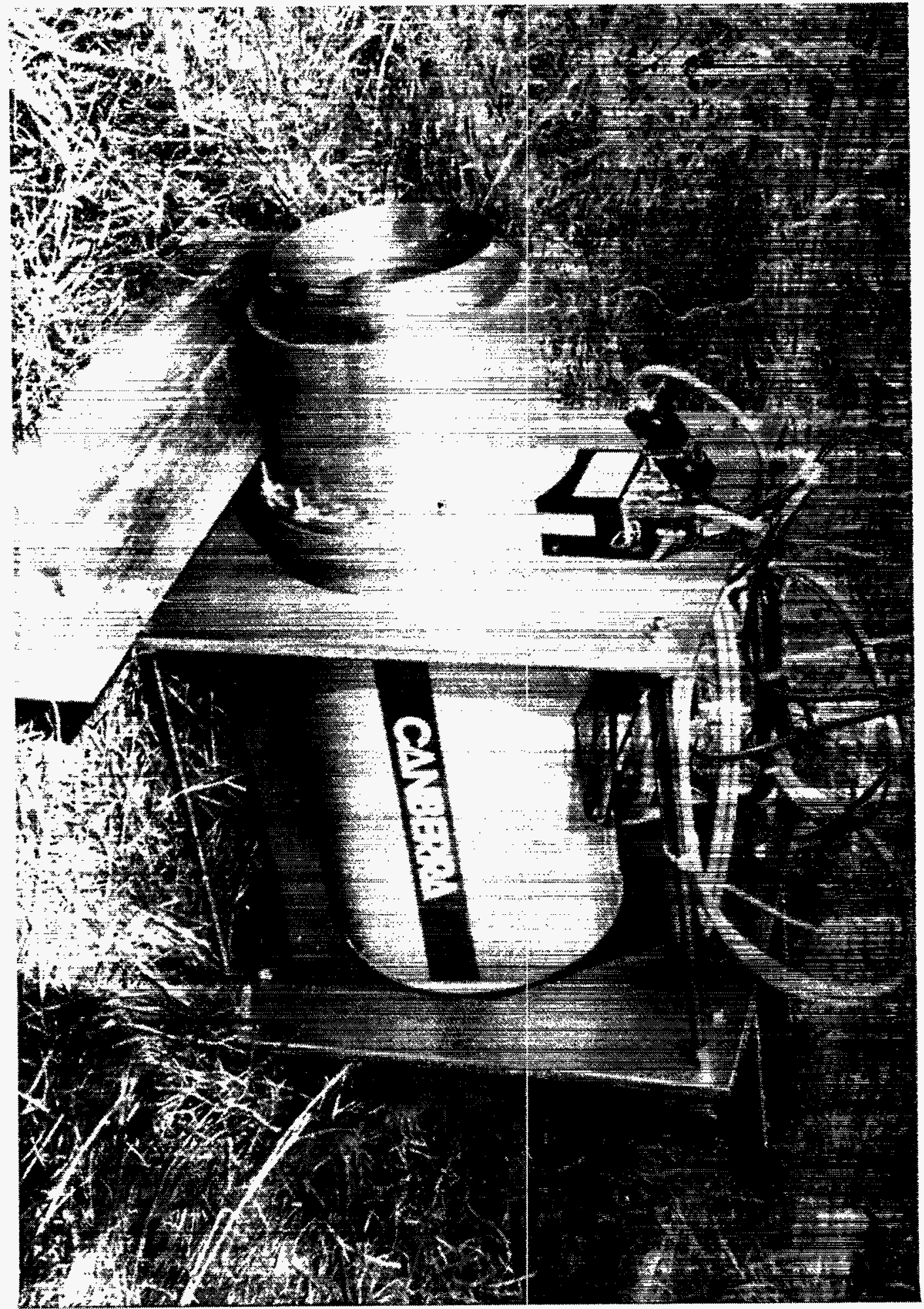




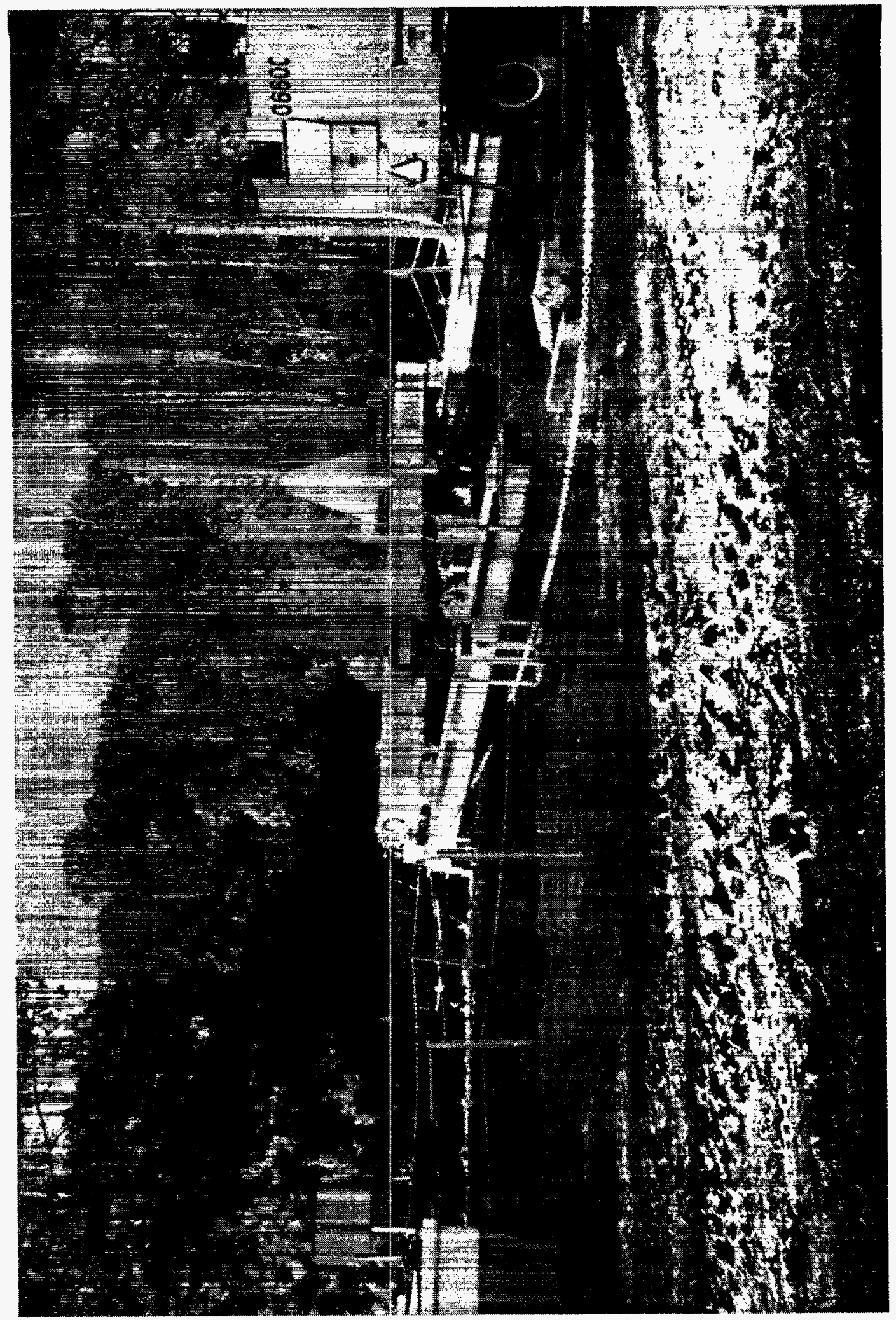

Figure 2. Photo of the trolley-based sensor deployment system. 
of additional sections of inexpensive track. The carriages are constructed primarily from aluminum with steel axles. At FBWU, four $2.44 \mathrm{~m}(8 \mathrm{ft})$ track sections were used, providing $9.75 \mathrm{~m}(32 \mathrm{ft})$ of $\mathrm{x}$-axis motion. The track rested on leveled steel I-beam foundations to ensure stability as shown in Figure 3. The trolley was moved to the back of the work area during digging operations and for changing or servicing the various sensors.

The bridge or y-axis assembly is constructed primarily from plywood and TJI joists formed into box beams. The bridge incorporates a set of rails to guide $y$-axis motion. Coupling between the bridge and the main beam carriages involves fitting a pipe into a box channel, making this operation very easy to accomplish with a small crane (Figure 4). The FBWU work employed a $7.31 \mathrm{~m}(24-\mathrm{ft})$ bridge that provided $6.1 \mathrm{~m}(20 \mathrm{ft})$ of $\mathrm{y}$-axis motion to span the pit. The bridge supports loads up to $181 \mathrm{~kg}$ (400 lbs) with a deflection of less than $0.318 \mathrm{~cm}(1 / 8 \mathrm{in})$. The bridge assembly weighs approximately $364 \mathrm{~kg}(800 \mathrm{lbs})$.

The mast assembly or z-axis consists of a horizontal rolling frame carrying a retractable vertical mast. The frame sets on the rails fixed atop the $y$-axis bridge beam and has motor driven wheels for traversing back and forth across the bridge during sensor scans. The mast can be extended about $3.05 \mathrm{~m}(10 \mathrm{ft})$ below the base of the bridge and retracted to a point near the base of the bridge. This permits scans to be conducted at the bottom of a $3.05 \mathrm{~m}(10-\mathrm{ft})$ pit while retaining the capability to retract the sensor and park the bridge completely off the pit. Sensors are attached to the mast with $1.27 \mathrm{~cm}(3 / 8 ")$ diameter by $15 \mathrm{~cm}$ (6-in.) long steel pins that fasten the mast end plates to the sensor plates (e.g., see Figure 1).

The trolley incorporates four separate motors to generate motion along the three axes. The two main beam carriages each have an integral motor. These drive the carriage wheels in tandem to provide $\mathrm{x}$-axis translation. The other two motors mount to the mast assembly. One motor propels the mast assembly drive wheels to translate the assembly across the bridge in the $y$-direction. The fourth motor raises and lowers the mast and sensor by spooling and unspooling a cable. The motors are of the stepper variety, which allow precise control over the amount of motion and supply feedback of distance traveled to the control computer. The trolley also employs radial encoders to track distance traveled on each axis. Once the encoders have been zeroed at an established home position they continuously output sensor coordinates in a repeatable rectangular coordinate system. Further information on the trolley can be found in Ref. 6.

\subsection{Data Handling System}

At FBWU the trolley motors, plastic scintillator and MLR were operated from a control station located approximately 15 to $30 \mathrm{~m}$ (50 to $100 \mathrm{ft}$ ) from the trolley in the site operations building. To accommodate remote operations, the data handling system uses radio frequency (RF) links for communication between the computer workstation console, the trolley and the active sensor. 


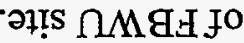

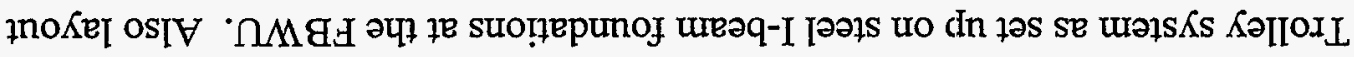

• $\varepsilon$ วmธิtม

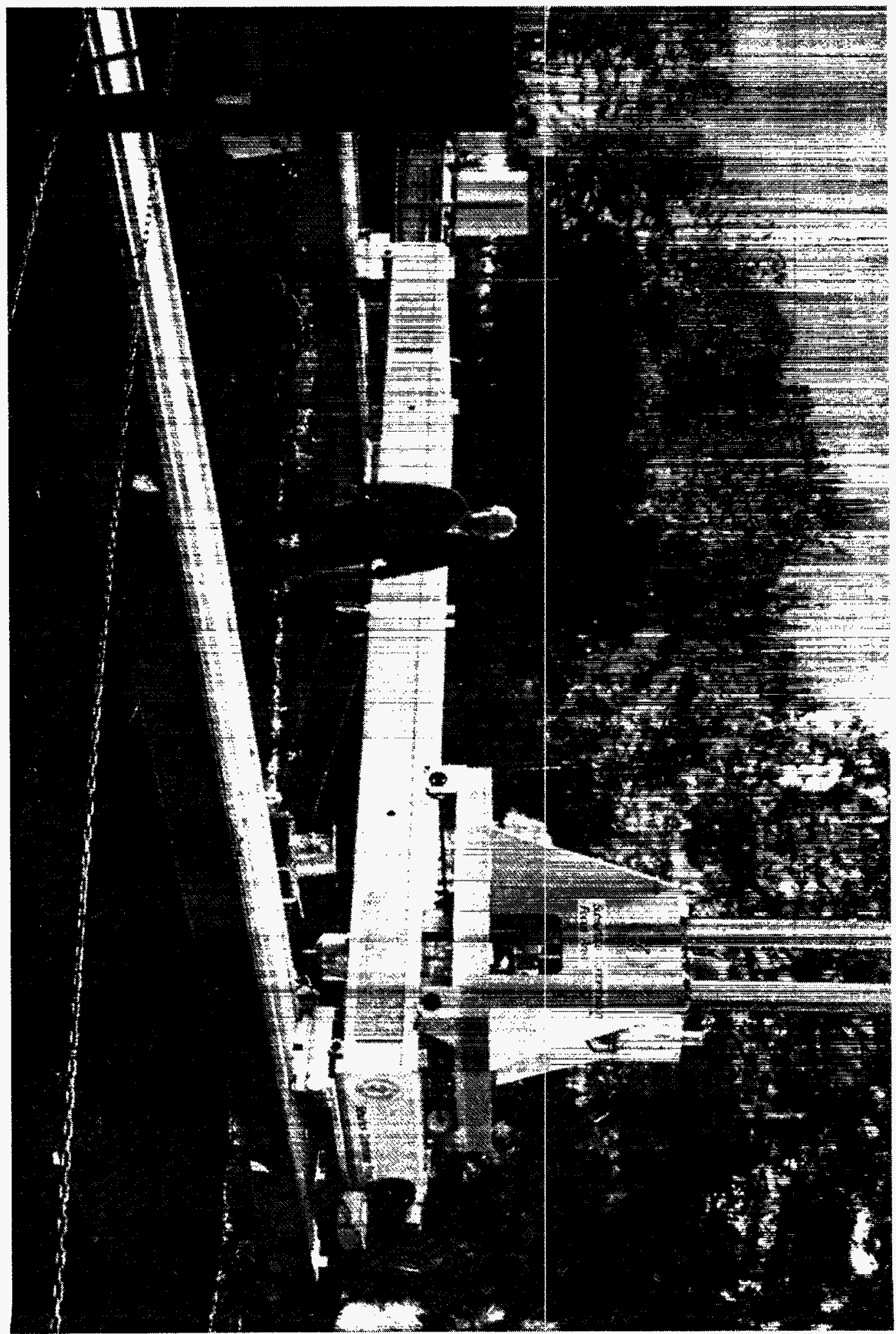




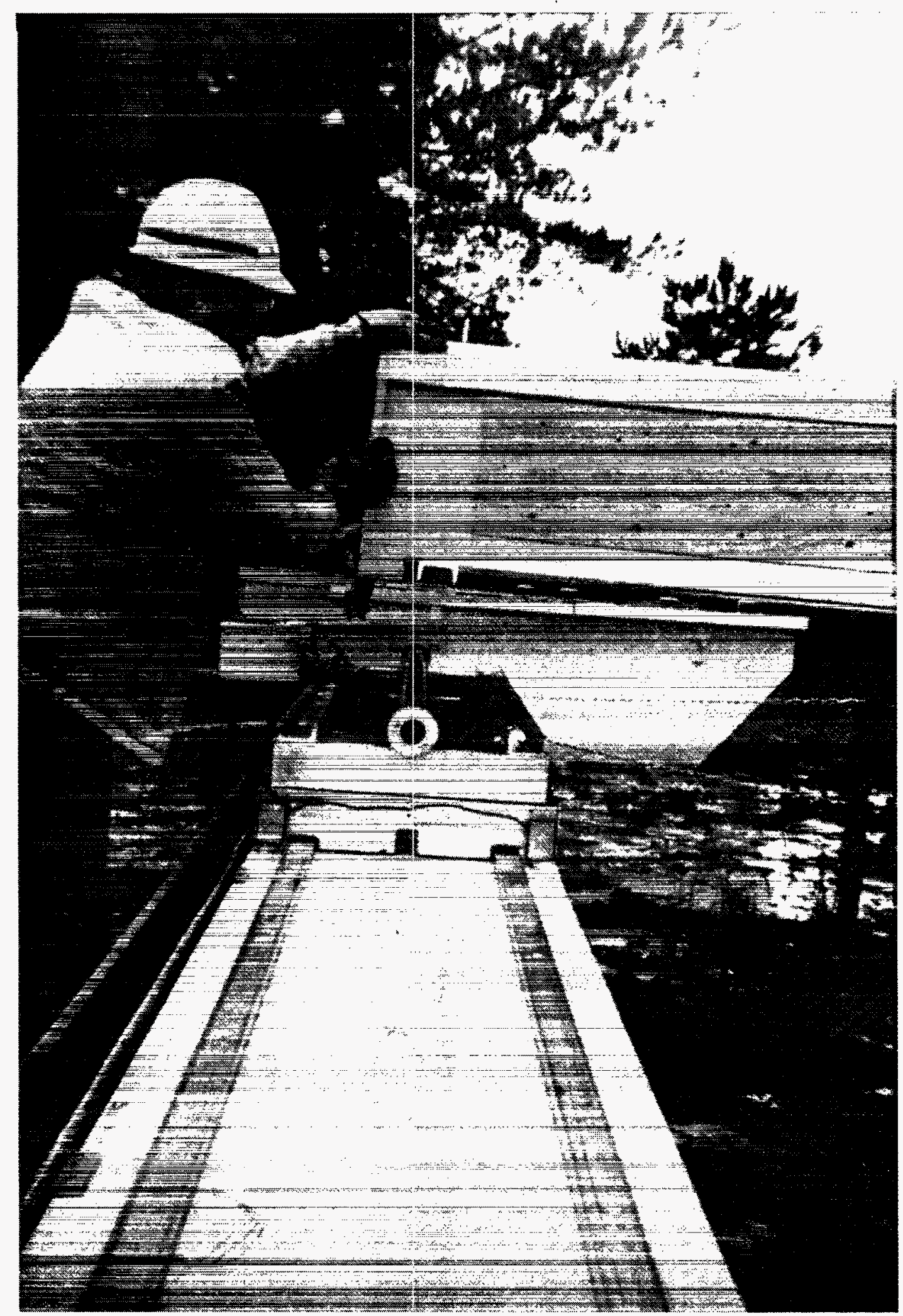

Figure 4. Coupling between the bridge and the main beam carriages. 
The MLR has an integral sensor control module that performs analog-to-digital conversion (if necessary) and provides one end of the two-way RF link. A communication antenna located outside the excavation exclusion zone provides the other end of the RF link. A coaxial cable connects the communication antenna to the operator workstation. By this arrangement, sensor on/off commands are transmitted to the sensors and digital sensor output is transmitted back to the operator workstation. Incoming data are displayed on the workstation console as they are acquired and are stored in files for post-processing. The Ge-spectrometer was controlled by a separate data acquisition system. This system has not yet been adapted for remote operations and requires RS232 cable between the multi channel analyzer (MCA) and the personal computer (PC) that controlled the spectrometer and analyzed and stored spectra.

A motor controller located on the trolley mast assembly and connected to the operator workstation by an RF link receives operator commands and energizes the motors as needed. The workstation computer monitors and records sensor position at all times. The sequence of motions required to make simple translations along each axis and to perform a complete area scan are preprogrammed and available to the operator through simple menu commands. Scan speeds and data spacing are also set by the operator.

\section{Detector Calibration}

The calibrations of the plastic and Ge detector systems are based on the following process.

1. For calibrated point or planar sources, the measured results are compared with model calculations to determine the accuracy of the modeling.

2. Volume sources are modeled to simulate various distributions of contamination horizontally and vertically resulting in a conversion factor for each distribution. One does not know the distribution of the ${ }^{137} \mathrm{Cs}$ activity in the soil, and each possible source distribution gives a different activity level.

3. For an actual distribution of contamination in the field, information defining the distribution is used to select the appropriate conversion factor to convert $\mathrm{c} / \mathrm{s}$ to $\mathrm{pCi} / \mathrm{g}$. In all cases a Beck soil composition with $20 \%$ moisture and a density of $1.5 \mathrm{~g} / \mathrm{cm}^{3}$ was assumed ${ }^{7}$.

The comparison of the results between these two (plastic and Ge) in situ detector systems and with soil samples that are collected and counted in the laboratory provides information on the quality of various detector calibrations, the plausibility of a particular assumed activity distribution and the agreement achievable between the different detectors and analysis methods for various distributions of contamination.

The model calculations were done primarily with the Monte Carlo photon and electron transport code CYLTRAN from the Integrated Tiger Series (ITS) of Coupled Electron/Photon Monte 
Carlo Code System ${ }^{8}$. This code is limited to calculations with cylindrical geometry, so rectangular areas are represented by a circle of the same area. A few calculations were done with the Monte Carlo Neutron Photon code MCNP in order to show that this limitation (use of CYLTRAN) was not significant for the results obtained here.

\subsection{Plastic Scintillation Detector}

In order to compare measured results with modeling calculations, the lower-level discriminator of the plastic detector had to be determined. For the measurements acquired at the FBWU, the energy setting of the lower-level discriminator was estimated by counting various point sources of radionuclides emitting monoenergetic $\gamma$ rays above and below the lower-level discriminator. Due to the relatively high level of the system noise the lower-level discriminator was estimated to be set at $150 \mathrm{keV}$. Afterward a procedure was developed for setting the discriminator. This was done with the use of the radioisotope sources ${ }^{137} \mathrm{Cs}$ (with $\gamma$ rays of $662 \mathrm{keV}$ ) and ${ }^{60} \mathrm{Co}(1252$ $\mathrm{keV}$ ). (The radionuclide ${ }^{60} \mathrm{Co}$ actually emits two gamma rays, one at $1173 \mathrm{keV}$ and one at 1332 $\mathrm{keV}$ of equal intensity giving an average energy of $1252 \mathrm{keV}$ ). Although the full-energy peaks $(E \gamma)$ are not detected with a plastic scintillation detector, the energies $\left(E_{e}\right)$ of their Compton edges are discernable as artifact peaks and are deduced from the equation:

$$
E_{e}=E_{\gamma}\left\{1-\left[1 /\left(1+2 E_{\gamma} / 511.0\right)\right]\right. \text {, }
$$

where the energies are in units of $\mathrm{keV}$. The energy vs spectral channel relation, $\mathrm{E}_{\mathrm{\gamma}}=\mathrm{a}+\mathrm{bX}$, is determined from the energies $E_{\gamma}$ and the respective channels $X_{\gamma}$ of these two edges. The details of the procedure for determining the lower-level discriminator setting are given in Appendix A.

The basic test of the modeling of the count rate for a given source activity was based on a set of three measurements with calibrated planar sources of ${ }^{137} \mathrm{Cs}$ from Analytics, Inc. ${ }^{9}$. Four square sources, each $60 \mathrm{~cm} \mathrm{x} 60 \mathrm{~cm}$, were purchased for this purpose. Measurements were made with the detector centered above a) one $60 \mathrm{~cm} \times 60 \mathrm{~cm}$ source $(1.8 \mu \mathrm{Ci}), \mathrm{b})$ all four sources in a 120 $\mathrm{cm} \times 120 \mathrm{~cm}$ array $(7.2 \mu \mathrm{Ci})$, and c) the array of four sources $(120 \times 120 \mathrm{~cm})$ counted four times to represent a $240 \mathrm{~cm} \times 240 \mathrm{~cm}$ planar source $(28.8 \mu \mathrm{Ci})$. The results of these counts are shown in columns 2 and 5 of Table 1 . The ratio of the measured counts/total $\gamma$ 's emitted goes down as the source size increases due to both the fact that the outer edge of the source is farther from the detector and more of these $\gamma$ rays are absorbed in the $\mathrm{Pb}$ shield around the detector. In contrast, the ratio of the measured counts $/ \gamma$ 's emitted per $\mathrm{cm}^{2}$ goes up since the outer edges of the sources do contribute some counts. 
Table 1. Plastic scintillation detector calibration for planar sources of $662-\mathrm{keV}$ photons. The statistical uncertainty for the modeled values are in parenthesis and represent one estimated standard deviation.

\begin{tabular}{|c|c|c|c|c|}
\hline \multirow{2}{*}{$\begin{array}{l}\text { Source area } \\
\qquad\left(\mathrm{cm}^{2}\right)\end{array}$} & \multicolumn{2}{|c|}{$\begin{array}{l}\text { Counts above cutoff per } 100 \gamma \text { 's } \\
\text { emitted }\end{array}$} & \multirow[b]{2}{*}{ Ratio } & \multirow{2}{*}{$\begin{array}{l}\text { Counts above cutoff } \\
\text { per } \gamma \text { per } \mathrm{cm}^{2}- \\
\text { measured }\end{array}$} \\
\hline & Measured & Modeled & & \\
\hline 3,600 & 1.986 & $1.700(3)$ & 1.17 & 71.5 \\
\hline 14,400 & 0.821 & $0.759(2)$ & 1.08 & 118 \\
\hline 57,600 & 0.2327 & $0.2250(11)$ & 1.03 & 134 \\
\hline
\end{tabular}

With the MCNP Monte Carlo code, this detector and the square sources were modeled as square objects. These results differed from the CYLTRAN results by less than $1 \%$, so these geometric approximations for CYLTRAN do not introduce a significant error.

The expected count rates for similar sources of $662-\mathrm{keV}$ photons were calculated with the CYLTRAN Monte Carlo code. The detector and sources were simulated by circular objects of the appropriate areas and volume. The shielding and detector mounting materials were included in the simulation and the same source-detector distance was used as in the measurements. This simulation provides a spectrum of the counts vs the energy lost in the detector. For this work, it was assumed that this spectrum represents the pulse height spectrum from the associated electronics; that is, it is assumed that the conversion of the energy lost in the detector to light and the of light to electronic pulse in the photomultiplier do not significantly alter the shape of the spectrum.

The areas of these computed spectra above an electronic cutoff of $150 \mathrm{keV}$ were computed. These results are shown in column 3 of Table 1 and differ from the measured values by 3 to $17 \%$ with the better agreement for the larger source areas. This is considered excellent agreement and supports two conclusions: a) the approximations in the modeling are reasonable and b) the modeling can be applied in other source configurations.

The spatial resolution of this detector was determined for a few source detector distances by measurements and by modeling calculations for point sources. This information is useful in the interpretation of the in situ measurements in terms of the actual spatial distributions of the activity. For both methods the count rate was determined as the source was moved away from the detector axis. These results are shown in Figure 5 and are in agreement that the count rate decreases a factor of 2 as the source moves horizontally about $30 \mathrm{~cm}$ from the vertical axis; that is, the full-width-half-maximum varies from 55 to $73 \mathrm{~cm}$ as the source-detector distance 

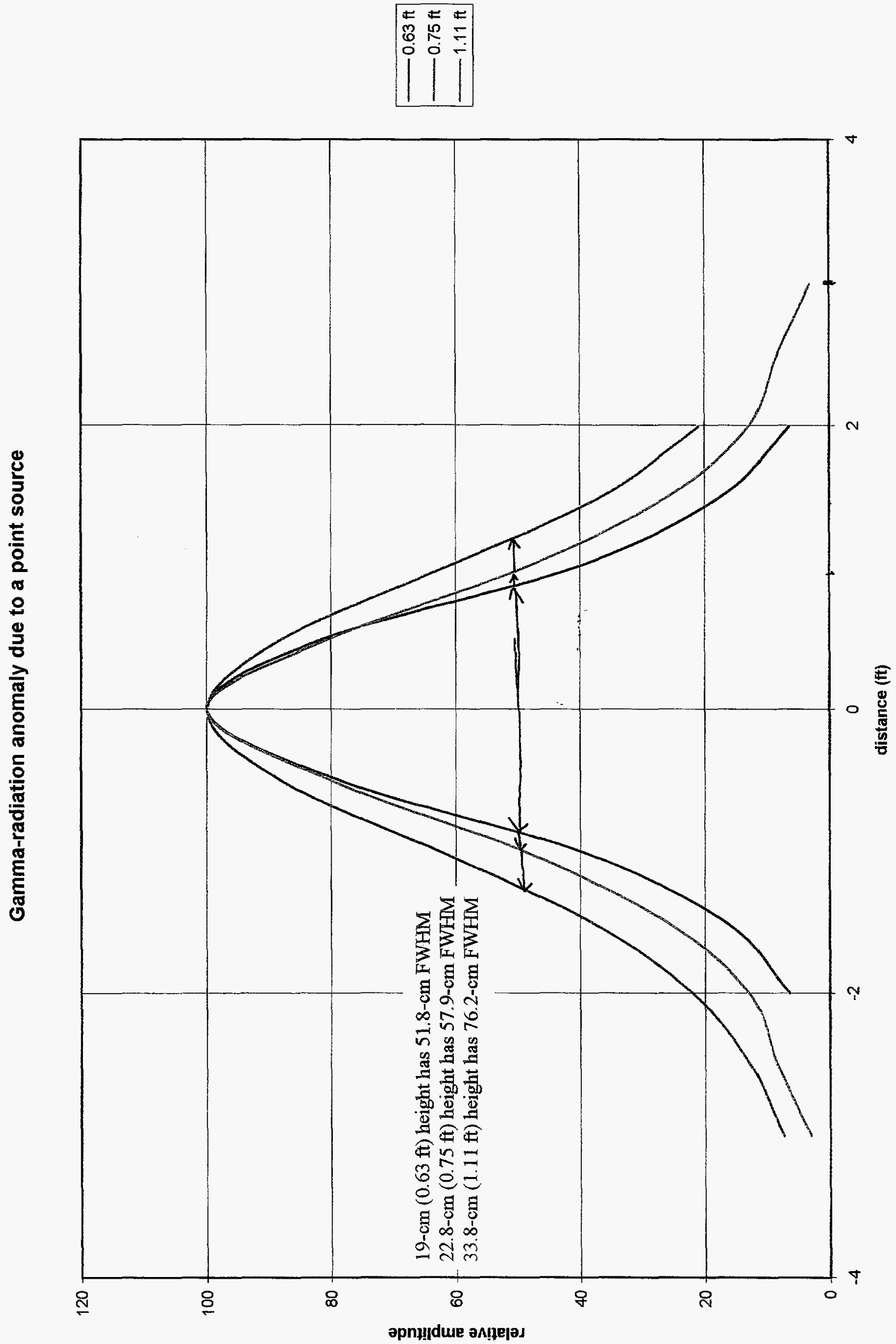

Figure 5. Plastic detector spatial resolution in full width at half maximum (FWHM) as determined with a point source at different source-to-detector distances. 
increases from 23 to $34 \mathrm{~cm}$. Therefore, a small area ( $<15 \mathrm{~cm}$ diameter) of high contamination would be mapped as an area $>55 \mathrm{~cm}$ diameter at FWHM for a source-detector distance of $23 \mathrm{~cm}$.

Due to unmitigating circumstances the background counting rate was not measured directly but rather deduced from a correlation of the counting rate of the plastic scintillation detector with the activity concentrations of the sample results. The $\mathrm{x}$ intercept of Figure 6, which shows the plot of sample activity concentration as a function of plastic scintillation detector count rate, is a measure of the background for a ${ }^{137} \mathrm{Cs}$ activity concentration of zero. Although this correlation is very good, comparison of the natural background peaks with the peak area of the $662-\mathrm{keV} \gamma$ ray peak in the Ge spectrum implied that the deduced background rate may be too large. As a result, the deduced activity concentrations of the contamination from the plastic scintillation detector may be too low. The lack of obtaining a directly measured background was an unfortunate serious shortcoming of this demonstration.

Although it is not directly a part of the calibration process, the model calculations for volume sources are included here. The volume sources are simulated by calculating the expected counts with CYLTRAN for disk sources (zero thickness) of selected radii at various depths in the soil. The counts at various depths can be combined to approximate the desired activity distribution. Although more complex distributions can be simulated in this manner, we have only simulated distributions that are uniform to a specified depth. These data are given in Table 2 for an electronic cutoff of $150 \mathrm{keV}$ for photons of $662 \mathrm{keV}$. 


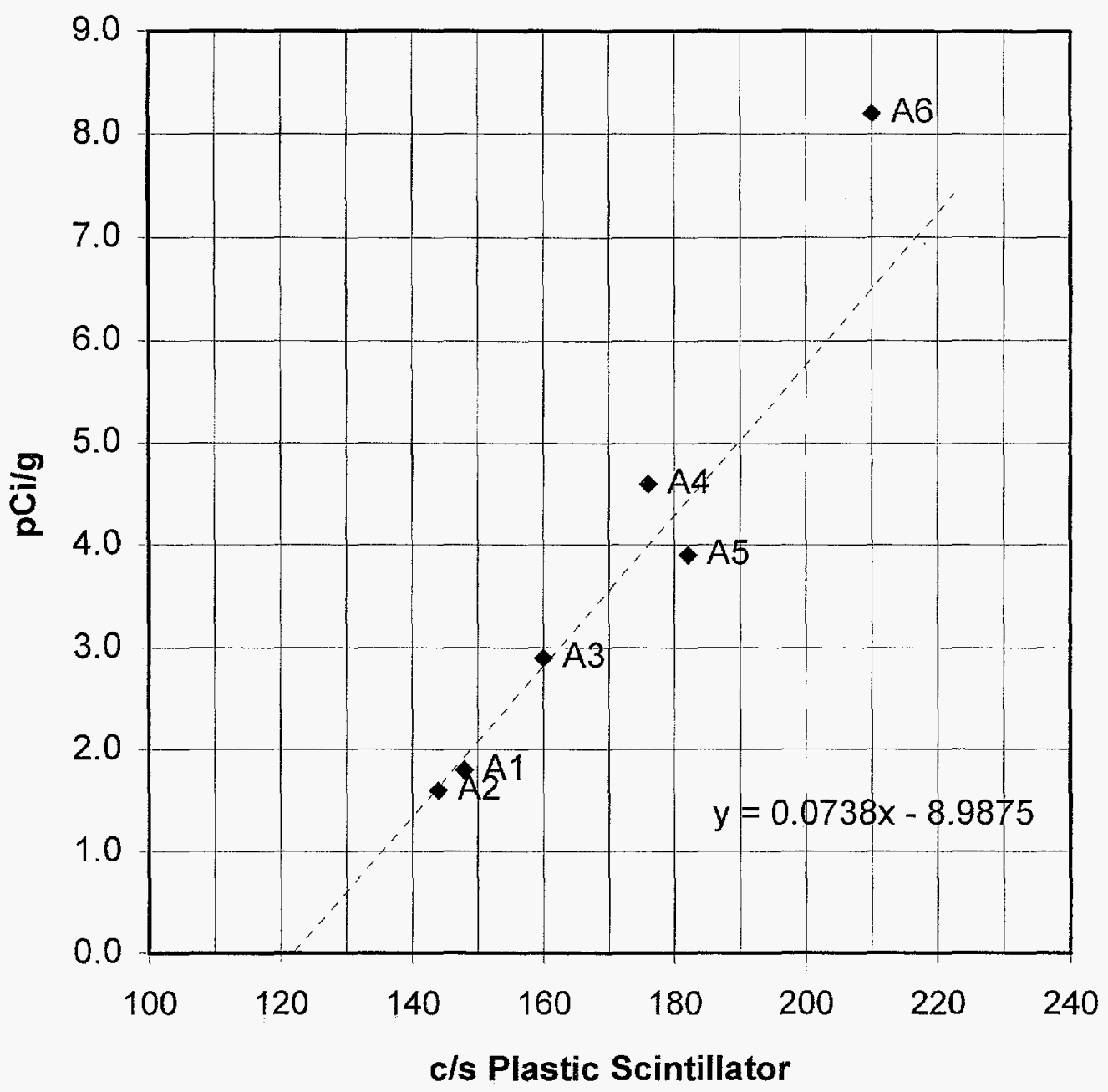

Figure 6. Plot of activity concentration from samples taken at locations indicated versus the counting rate of the plastic scintillation detector at the same location. The $\mathrm{x}$ intercept is one measure of the plastic scintillator background rate. 
Table 2. Plastic scintillation detector modeled calibration for disk sources of various diameters at various depths in soil with density of $1.5 \mathrm{~g} / \mathrm{cm}^{3}$ and deduced volume source calibrations.

\begin{tabular}{|c|c|c|c|c|c|}
\hline \multirow{2}{*}{$\begin{array}{c}\text { Source } \\
\text { diameter } \\
\text { (cm) }\end{array}$} & \multirow[b]{2}{*}{$\begin{array}{c}\text { Depth } \\
\text { (cm) }\end{array}$} & \multirow{2}{*}{$\begin{array}{c}\text { Disk source } \\
\text { (counts } / 100 \\
\gamma) \text { emitted }\end{array}$} & \multicolumn{3}{|c|}{ Volume source, counts $/ 100 \gamma$ emitted } \\
\hline & & & $\begin{array}{c}\text { uniform to } \\
3 \mathrm{~cm}\end{array}$ & $\begin{array}{l}\text { uniform } \\
\text { to } 9.2 \mathrm{~cm}\end{array}$ & $\begin{array}{l}\text { uniform to } \\
15.2 \mathrm{~cm}\end{array}$ \\
\hline 0 & 0.0 & 2.181 & & & \\
\hline 10 & 0.0 & 2.141 & & & \\
\hline 10 & 1.5 & 1.934 & 1.93 & \multirow{3}{*}{1.43} & \multirow{5}{*}{1.081} \\
\hline & 4.6 & 1.376 & & & \\
\hline & 7.6 & 0.972 & & & \\
\hline & 10.7 & 0.662 & & & \\
\hline & 13.7 & 0.462 & & & \\
\hline 120 & 0.0 & 0.834 & & & \\
\hline \multirow[t]{5}{*}{120} & 1.5 & 0.727 & \multirow[t]{3}{*}{0.727} & \multirow{5}{*}{0.530} & \multirow{5}{*}{0.402} \\
\hline & 4.6 & 0.509 & & & \\
\hline & 7.6 & 0.354 & & & \\
\hline & 10.7 & 0.247 & & & \\
\hline & 13.7 & 0.173 & & & \\
\hline
\end{tabular}

\subsection{Ge Semiconductor Detector}

There are two sets of measurements with the thin window, extended-range Ge detector that demonstrate the accuracy of the modeling. The first set made use of the same large area ${ }^{137} \mathrm{Cs}$ sources as used for the plastic scintillator and discussed in Sect. 3.1. These results are shown in Table 3 for both the 32-36-keV barium $(\mathrm{Ba}) \mathrm{K}$ series $\mathrm{x}$ rays and the $662-\mathrm{keV} \gamma$ ray. 
Table 3. Ge Semiconductor detector calibration for planar sources

\begin{tabular}{|c|c|c|c|c|c|}
\hline \multirow{2}{*}{$\begin{array}{l}\text { Source area } \\
\qquad\left(\mathbf{c m}^{2}\right)\end{array}$} & \multirow{2}{*}{$\begin{array}{c}\text { Photon } \\
\text { energy } \\
\text { (keV) }\end{array}$} & \multicolumn{2}{|c|}{$\begin{array}{l}\text { Counts in peak per } 100 \\
\text { photons emitted }\end{array}$} & \multirow[b]{2}{*}{ Ratio } & \multirow{2}{*}{$\begin{array}{c}\text { Counts in } \\
\text { peak per } \gamma \\
\text { per } \mathrm{cm}^{2} \\
\text { measured }\end{array}$} \\
\hline & & Measured & Modeled & & \\
\hline \multirow[t]{2}{*}{3,600} & $32-36$ & $0.0456(15)$ & 0.0603 & 0.76 & 1.64 \\
\hline & 662 & $0.00619(13)$ & 0.00686 & 0.90 & 0.223 \\
\hline \multirow[t]{2}{*}{14,400} & $32-36$ & $0.0119(4)$ & 0.0159 & 0.75 & 1.71 \\
\hline & 662 & $0.00164(3)$ & 0.00173 & 0.95 & 0.236 \\
\hline
\end{tabular}

For $\mathrm{Ba} \mathrm{Kx}$ rays, the modeling calculations were done at 32.1 and $36.6 \mathrm{keV}$ and an average, weighted by the relative emission probabilities of the two components, was computed. The agreement for the $662-\mathrm{keV}$ line is quite satisfactory, especially for the large source area, but that for the $\mathrm{K} x$ ray is not as good as expected. However, for the use in section $\mathrm{V}$ of the $\mathrm{K} x$ ray intensity, this difference does not cause any difficulty.

The second set of measurements were with a point source of europium- $152\left({ }^{152} \mathrm{Eu}\right)$ that was counted at various distances from the detector axis on the "soil" surface. These measurements were for $\gamma$-ray energies of 121,344 , and $1408 \mathrm{keV}$. As long as the source "sees" the detector, the values agree from 0.7 to $6.5 \%$. When the source is shielded, the efficiency becomes very small and the percentage differences increase, but the contribution to the peak area for a uniform source would be quite small.

From these data it is concluded that the modeling for a specific source distribution (i.e., with a known area and depth distribution) can be done with sufficient accuracy, say $10-15 \%$ for purposes of meeting cleanup criteria. The important factor is being able to model the depth distribution accurately.

As for the Ge spectrometer, the count expected from uniform distributions of ${ }^{137} \mathrm{Cs}$ in volume sources with diameters of 10 and $120 \mathrm{~cm}$ were computed from modeling of disks at various depths in the soil. These results are given in Table 4. 
Table 4. Ge semiconductor detector counts for $662-\mathrm{keV} \gamma$ ray from modeling for disk sources of various radii and depth in soil (density $1.5 \mathrm{~g} / \mathrm{cm}^{3}$ ) and deduced volume source values.

\begin{tabular}{|c|c|c|c|c|c|}
\hline \multirow{2}{*}{$\begin{array}{c}\text { Source of } \\
\text { uniform } \\
\text { activity } \\
\text { concentration } \\
\text { diameter (cm) }\end{array}$} & \multirow[b]{2}{*}{$\begin{array}{c}\text { Depth } \\
\text { (cm) }\end{array}$} & \multirow{2}{*}{$\begin{array}{c}\text { Disk source } \\
\begin{array}{c}\text { Counts } / 100 \\
\text { emitted }\end{array}\end{array}$} & \multicolumn{3}{|c|}{ Volume source, counts $/ 100 \gamma$ emitted } \\
\hline & & & $\begin{array}{l}\text { uniform } \\
\text { to } 3 \mathrm{~cm}\end{array}$ & $\begin{array}{l}\text { uniform to } \\
9.2 \mathrm{~cm}\end{array}$ & $\begin{array}{c}\text { uniform to } \\
15.2 \mathrm{~cm}\end{array}$ \\
\hline 10 & 0.0 & 0.0303 & & & \\
\hline \multirow[t]{5}{*}{10} & 1.5 & 0.0228 & 0.0228 & \multirow{3}{*}{0.0142} & \multirow{5}{*}{0.00984} \\
\hline & 4.6 & 0.01262 & & & \\
\hline & 7.6 & 0.00723 & & & \\
\hline & 10.7 & 0.00413 & & & \\
\hline & 13.7 & 0.00243 & & & \\
\hline - & & & & & \\
\hline 120 & 0.0 & 0.00246 & & & \\
\hline \multirow[t]{5}{*}{120} & 1.5 & 0.00198 & 0.00198 & \multirow{3}{*}{0.00136} & \multirow{5}{*}{0.00101} \\
\hline & 4.6 & 0.00127 & & & \\
\hline & 7.6 & 0.000823 & & & \\
\hline & 10.7 & 0.000596 & & & \\
\hline & 13.7 & 0.000369 & & & \\
\hline
\end{tabular}

For later use it is of interest to tally the $\mathrm{K} \mathrm{x} / \gamma$ ratio for ${ }^{137} \mathrm{Cs}$ as a function of the source diameter and depth in the soil. The variation of the efficiency for the $662-\mathrm{keV} \gamma$ ray is given in Table 3 and a similar tally for $32-\mathrm{keV}$ photons, the dominant portion of the $\mathrm{Kx}$ ray peak, is given in Table 5. 
Table 5. Ge detectors counts in $\mathrm{Ba} \mathrm{K} \alpha$ peak from modeling

\begin{tabular}{|c|c|c|c|c|c|}
\hline \multicolumn{2}{|c|}{ Source } & \multirow{2}{*}{$\begin{array}{c}\text { disk } \\
\text { counts/ } \\
100 \gamma \\
\text { emitted }\end{array}$} & \multicolumn{3}{|c|}{$\begin{array}{c}\text { counts in } B a K \alpha \text { peak per } 100 \text { photons emitted } \\
\text { modeled }\end{array}$} \\
\hline $\begin{array}{l}\text { diameter } \\
(\mathrm{cm})\end{array}$ & $\begin{array}{c}\text { depth } \\
\text { (cm) }\end{array}$ & & $\begin{array}{l}\text { uniform to } \\
3 \mathbf{c m}\end{array}$ & $\begin{array}{l}\text { uniform to } \\
9.2 \mathrm{~cm}\end{array}$ & $\begin{array}{l}\text { uniform to } \\
15.2 \mathrm{~cm}\end{array}$ \\
\hline 10 & 0 & 0.280 & & & \\
\hline \multirow[t]{5}{*}{10} & 0.3 & 0.210 & \multirow{5}{*}{0.081} & & \\
\hline & 0.9 & 0.106 & & & \\
\hline & 1.5 & 0.0519 & & & \\
\hline & 2.1 & 0.0255 & & 0.0279 & \\
\hline & 2.7 & 0.0125 & & & 0.0167 \\
\hline 120 & 0 & 0.0209 & & & \\
\hline \multirow[t]{5}{*}{120} & 0.3 & 0.0147 & & & \\
\hline & 0.9 & 0.00707 & & & \\
\hline & 1.5 & 0.00338 & 0.0055 & & \\
\hline & 2.1 & 0.00162 & & 0.00189 & \\
\hline & 2.7 & 0.00079 & & & 0.00113 \\
\hline
\end{tabular}

The values needed to complete the counts from the source below $2.7 \mathrm{~cm}$ have been estimated from the rate of decrease with depth for the values in Table 5.

The relative intensities of the $\mathrm{K}_{\alpha} \mathrm{x}$ rays and $662-\mathrm{keV} \gamma$ rays can be combined with the data in Tables 4 and 5 to compute the expected $\mathrm{K}_{\alpha} / \gamma$, ratio for the various source distributions. These intensities are $\mathrm{I}_{\mathrm{K} \alpha}=5.82$ and $\mathrm{I}_{\gamma}=85.2$ per 100 decays of ${ }^{137} \mathrm{Cs}^{10}$. The deduced $\mathrm{K}_{\alpha} / \gamma$ peak area ratios from modeling are given in Table 6. 
Table 6. Modeled $\mathrm{K}_{\mathrm{e}} / \gamma$ peak area ratios for various ${ }^{137} \mathrm{Cs}$ source distributions.

\begin{tabular}{|c|c|c|c|c|c|}
\hline \multirow{2}{*}{$\begin{array}{c}\text { Source } \\
\text { diameter } \\
(\mathbf{c m})\end{array}$} & \multicolumn{4}{|c|}{$\left(K_{\alpha}\right) / \gamma$ peak area ratio from modeling } & \multirow{2}{*}{$\begin{array}{c}\left(K_{\alpha}\right) / \gamma \text { peak } \\
\text { area ratio } \\
\text { scaled by } \\
18 \%\end{array}$} \\
\hline & $\begin{array}{l}\text { disk on } \\
\text { surface }\end{array}$ & $\begin{array}{c}\text { uniform to } \\
3 \mathbf{c m}\end{array}$ & $\begin{array}{c}\text { uniform to } \\
9.2 \mathrm{~cm}\end{array}$ & $\begin{array}{c}\text { uniform to } \\
15.2 \mathrm{~cm}\end{array}$ & \\
\hline 10 & 0.633 & 0.243 & 0.135 & 0.116 & 0.095 \\
\hline 120 & 0.582 & 0.190 & 0.095 & 0.077 & 0.063 \\
\hline
\end{tabular}

As noted in Table 3, the measured ratio of the efficiencies for the $\mathrm{K}_{\alpha} \mathrm{x}$-rays and the $662-\mathrm{keV} \gamma$ rays, $\epsilon_{\mathrm{K} \alpha} / \epsilon_{\gamma}$, is lower than the modeled value by about $18 \%$. Therefore, it is possible that all of the values in Table 6 should be reduced by this amount, so, for example, the uniform to $15.2 \mathrm{~cm}$ values would be 0.095 and 0.063 as given in the last column of Table 6 .

From the data in Tables 2 and 4 , one can compute factors that convert measured count rates from the plastic scintillation and $\mathrm{Ge}$ semiconductor detectors to soil contamination levels in, for example, $\mathrm{pCi} / \mathrm{g}$. However, it must be emphasized that these conversion factors only apply to these idealized source distributions.

For convenience, the count rate expected for a contamination level of $1.0 \mathrm{pCi} / \mathrm{g}$ has been computed. These results are given in Table 7 . 
Table 7. Count rates expected in plastic scintillation and Ge semiconductor detectors for volume sources of ${ }^{137} \mathrm{Cs}$ at $1.0 \mathrm{pCi} / \mathrm{g}$ and soil density of $1.5 \mathrm{~g} / \mathrm{cm}^{3}$.

\begin{tabular}{|l|l|l|l|}
\hline \multicolumn{2}{|c|}{ Source } & \multicolumn{1}{c|}{$\begin{array}{c}\text { Plastic scintillation } \\
\text { counts/s above 150- } \\
\text { keV cutof }\end{array}$} & $\begin{array}{c}\text { Ge detector } \gamma \text { peak } \\
\text { counts/s }\end{array}$ \\
\hline 10 & \multicolumn{1}{|c|}{$\begin{array}{c}\text { uniform to depth } \\
(\mathbf{c m})\end{array}$} & 0.21 & $2.5 \times 10^{-3}$ \\
\hline & 3.0 & 0.49 & $9.48 \times 10^{-2}$ \\
\hline & 9.2 & 0.61 & $5.5 \times 10^{-3}$ \\
\hline & 15.2 & & \\
\hline 120 & & 11.6 & $3.2 \times 10^{-2}$ \\
\hline & 3.0 & 26.0 & $6.7 \times 10^{-2}$ \\
\hline & 9.2 & 32.6 & $8.2 \times 10^{-2}$ \\
\hline
\end{tabular}

\section{In situ radiation measurements at FBWU}

\subsection{Sequence of Measurements}

Figures 7 and 8 show the layout of the FBWU site along with results of a preliminary $\gamma$ radiation survey conducted with hand-held NaI (T1) detectors. During the pre cleanup survey, the detector probe was held $5 \mathrm{~cm} \mathrm{(2")} \mathrm{above} \mathrm{the} \mathrm{ground} \mathrm{while} \mathrm{a} \mathrm{technician} \mathrm{walked} \mathrm{over} \mathrm{the} \mathrm{waste} \mathrm{unit.}$ Surface contamination was not found outside the site boundary (see Figure 8). The count rates within the controlled area ranged from $100 \mathrm{cpm}$ to $10,000 \mathrm{cpm}$. The INEEL trolley was positioned so that the principal radiation hot spot on the east end of the site boundary and the neighboring area could be scanned as shown in Figure 7. An initial plastic scintillator scan was conducted at a mean detector height of $24.4 \mathrm{~cm}(0.8 \mathrm{ft})$. The plastic scintillation detector case to ground height varied from $36.9 \mathrm{~cm}$ at position A01 to $18.0 \mathrm{~cm}$ at position A14. After review of the plastic scintillator data, 19 positions along a diagonal of the excavating area were identified at which ${ }^{137} \mathrm{Cs}$ activity concentrations were to be measured. In situ Ge-spectrometer measurements were made at 6 of these locations and soil samples were collected for lab analysis at all 19 positions. The Ge measurements were all made with the collimator face $15 \mathrm{~cm}(6 ")$ from the ground. The site was then excavated to a depth of $15-45 \mathrm{~cm}(0.5-1.5 \mathrm{ft})$ with the deepest excavation occurring in the vicinity of the hotspot. A second plastic scintillator scan was conducted at a mean detector height of $21.3 \mathrm{~cm}(0.7 \mathrm{ft})$ after this excavation. Heavy rains had produced standing water over large portions of the excavation at the time of the second scan. Table 8 gives a summary of the pre- and post-excavation plastic scintillator measurements. 


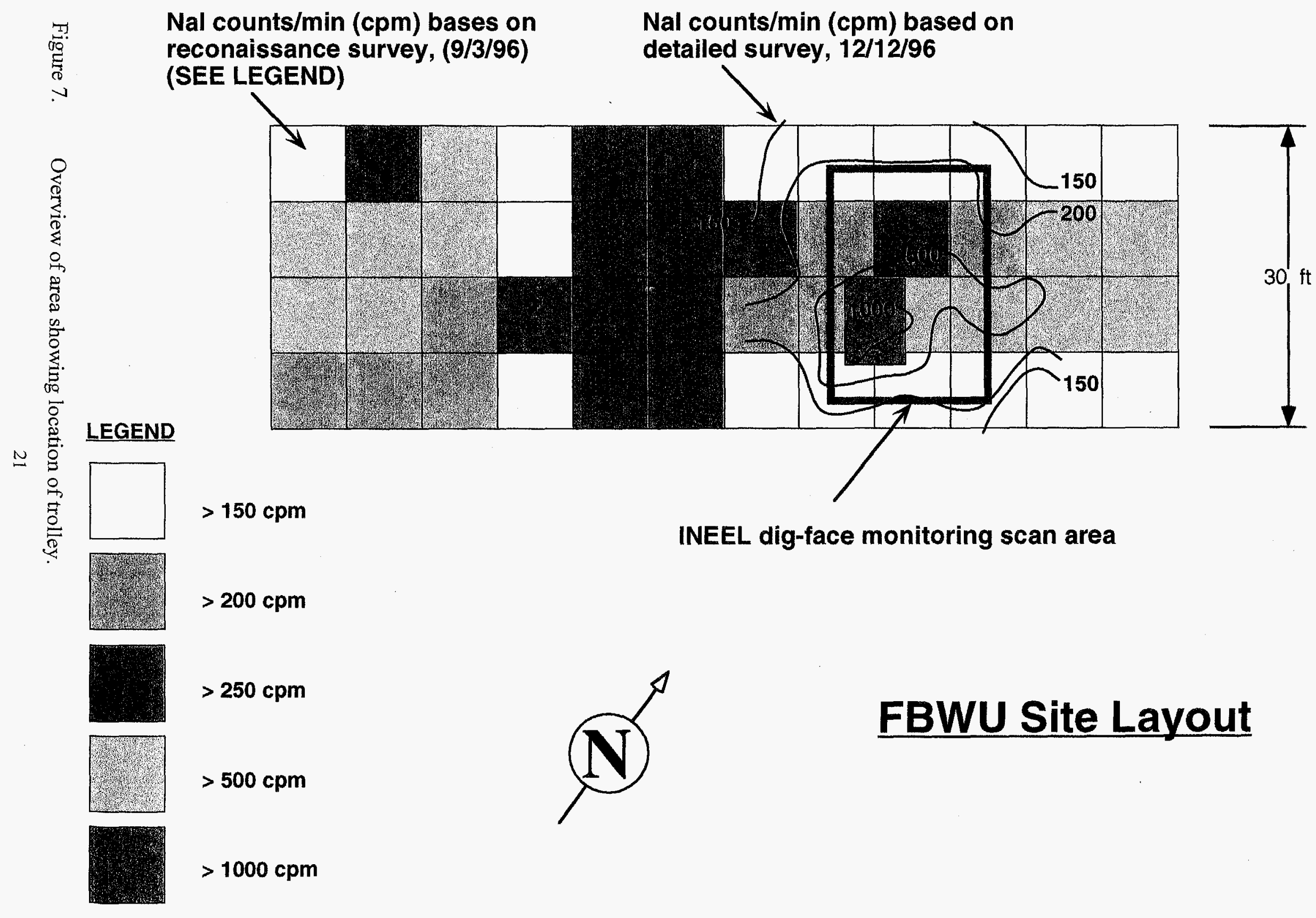


GRAVEL AREA

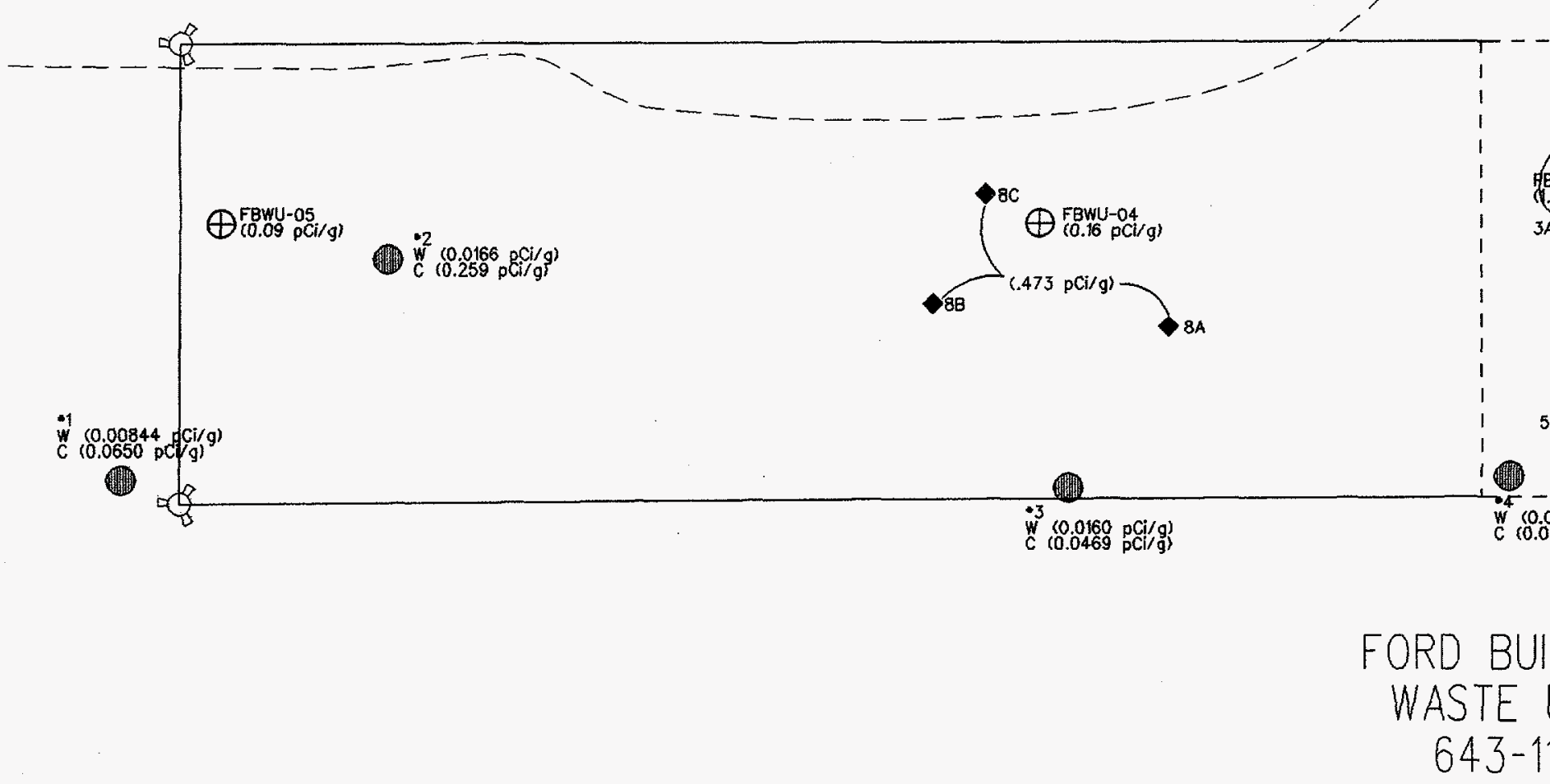

\section{LEGEND}

COUNTS PER MINUTE USING SODIUM IODIDE DETECTOR CALIBRATED TO Cs-137

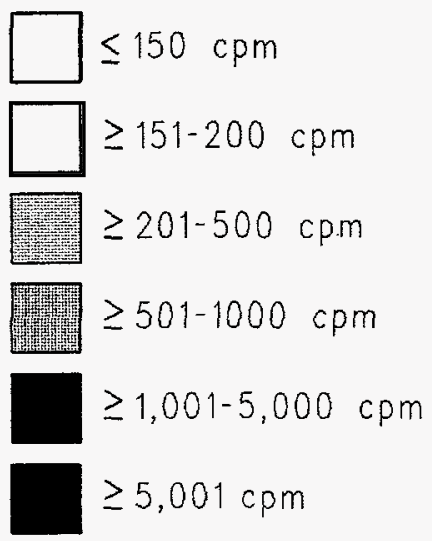

- - UNDERGROUND RADIOACTIVE MATERIAL AREA

(17) TREES (WOOD, CROWN CS-137 RESULTS)

$\oplus$ SOIL BORING (CS-137 RESULTS)

- composite sample

o SITE BOUNDARY

7 soll contamination area

Figure 8. Overview of area showing some me and hand-held $\mathrm{NaI}(\mathrm{T} 1)$ measuremen 


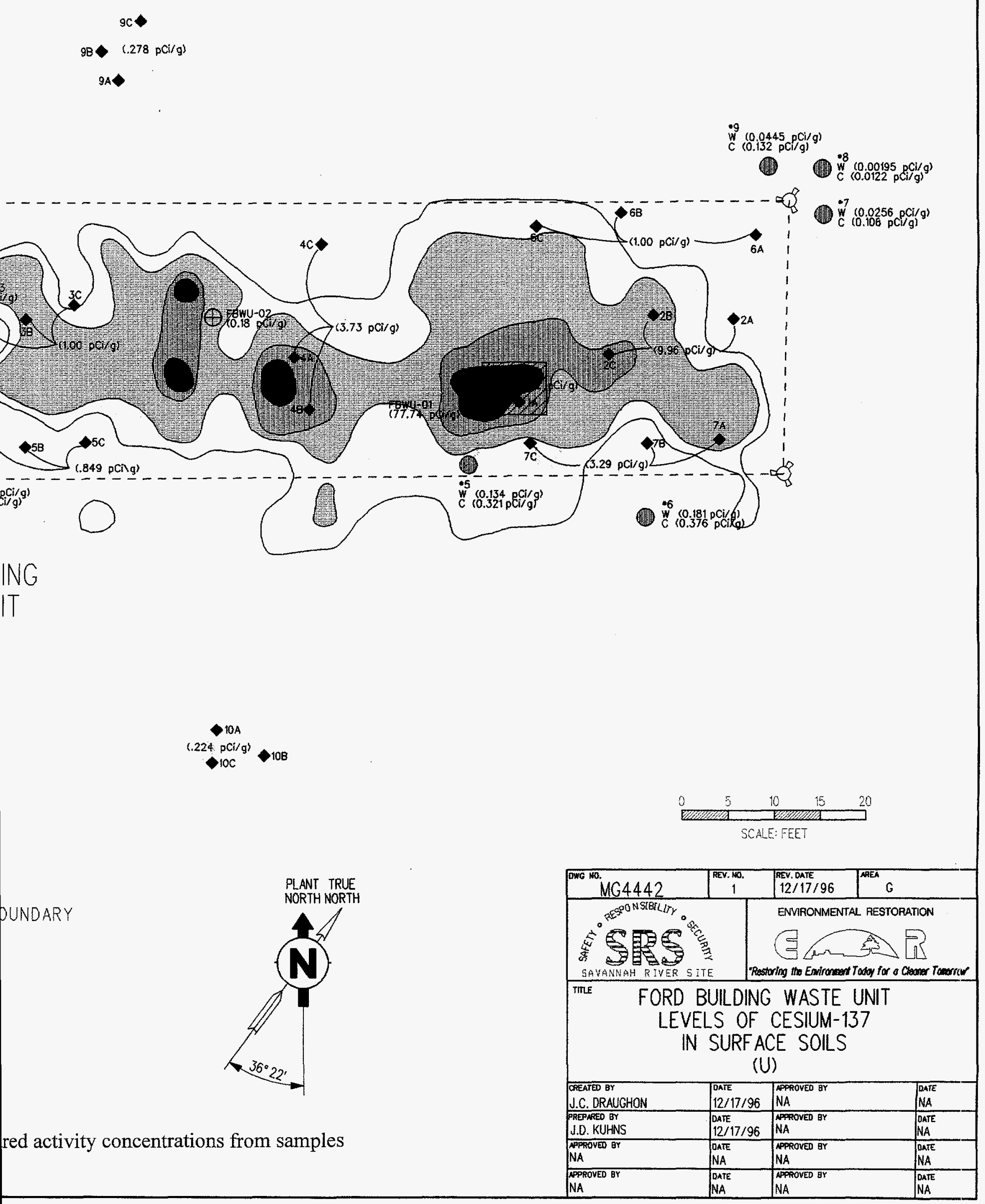


Table 8. Summary of measurements with plastic scintillator mounted on INEEL trolley.

\begin{tabular}{|l|c|c|c|c|c|}
\hline \multicolumn{1}{|c|}{ Scan } & \# radiation & $\begin{array}{c}\text { mean } \\
\text { ground } \\
\text { measurements }\end{array}$ & $\begin{array}{c}\text { mean } \\
\text { detector } \\
\text { height } \\
\text { above } \\
\text { ground }\end{array}$ & $\begin{array}{c}\text { range of } \\
\text { ground } \\
\text { elevation }\end{array}$ & $\begin{array}{c}\text { range of } \\
\text { detector } \\
\text { heights above } \\
\text { ground }\end{array}$ \\
\hline pre-excavation & 3241 & $115.8 \mathrm{~cm}$ & $24.4 \mathrm{~cm}$ & $91.4-137.2 \mathrm{~cm}$ & $6.1-36.6 \mathrm{~cm}$ \\
& & $(3.8 \mathrm{ft})$ & $(0.8 \mathrm{ft})$ & $(3.0-4.5 \mathrm{ft})$ & $(0.2-1.2 \mathrm{ft})$ \\
\hline post- & 1431 & $94.5 \mathrm{~cm}$ & $21.3 \mathrm{~cm}$ & $76.2-106.7 \mathrm{~cm}$ & $6.1-36.6 \mathrm{~cm}$ \\
excavation & & $(3.1 \mathrm{ft})$ & $(0.7 \mathrm{ft})$ & $(2.5-3.5 \mathrm{ft})$ & $(0.2-1.2 \mathrm{ft})$ \\
\hline
\end{tabular}

\subsection{Pre-excavation $\gamma$ radiation}

Figure 9 shows the $\gamma$ radiation data in counts/s from the pre-excavation plastic scintillator scan. The map shows a prominent peak corresponding to the recognized ${ }^{137} \mathrm{Cs}$ hot spot. Measurements near this hot spot exceed 1400 counts/s. Three other radiation peaks are observed in the vicinity of the major peak. These secondary peaks have much lower amplitudes $(\sim 300-400$ counts/s) and somewhat smaller size compared with the main hot spot. The four hot spots are superimposed on a more constant radiation field that decreases toward the $(0,0)$ corner of the data set. Radiation measurements near this corner average around 150 counts/s. Most likely these count values are still elevated above natural background since measured radiation levels are still decreasing at the point where the data set terminates.

The plastic scintillator data shows the same general pattern of ${ }^{137} \mathrm{Cs}$ distribution as indicated by the hand held detector data in Figure 8. The spatial fidelity of the radiation field as mapped by the plastic scintillator is clearly superior to the results obtained using hand held detectors simply due to the larger number of data points and their well-defined locations. This is illustrated by the fact that the secondary hotspots are not distinguishable in the hand held detector data. By their size these secondary hotspots may, indeed, be hot particles (point sources) and therefore difficult to locate with hand held detectors. Higher fidelity with the plastic scintillator map may result from a greater consistency in the measurement procedure and from the many measurements.

Figure 9 also shows the location of 19 soil samples that were collected and analyzed in the laboratory. These soil cores were collected to a depth of $7.6 \mathrm{~cm} \mathrm{(3")} \mathrm{and} \mathrm{were} \mathrm{homogenized} \mathrm{for}$ lab analysis. In situ Ge-spectrometer measurements were made at six of the sample locations (i.e., A01, A09, A10, A11, A12, and A13) prior to the collection of the samples for laboratory analysis.

\subsection{Post-excavation $\gamma$ radiation}

Figure 10 shows the radiation field mapped by the plastic scintillator following excavation. Note that the color scale for Figure 10 is significantly expanded relative to the color scale used in Figure 9. The highest radiation level recorded after excavation was $\sim 160$ counts/s. Radiation 


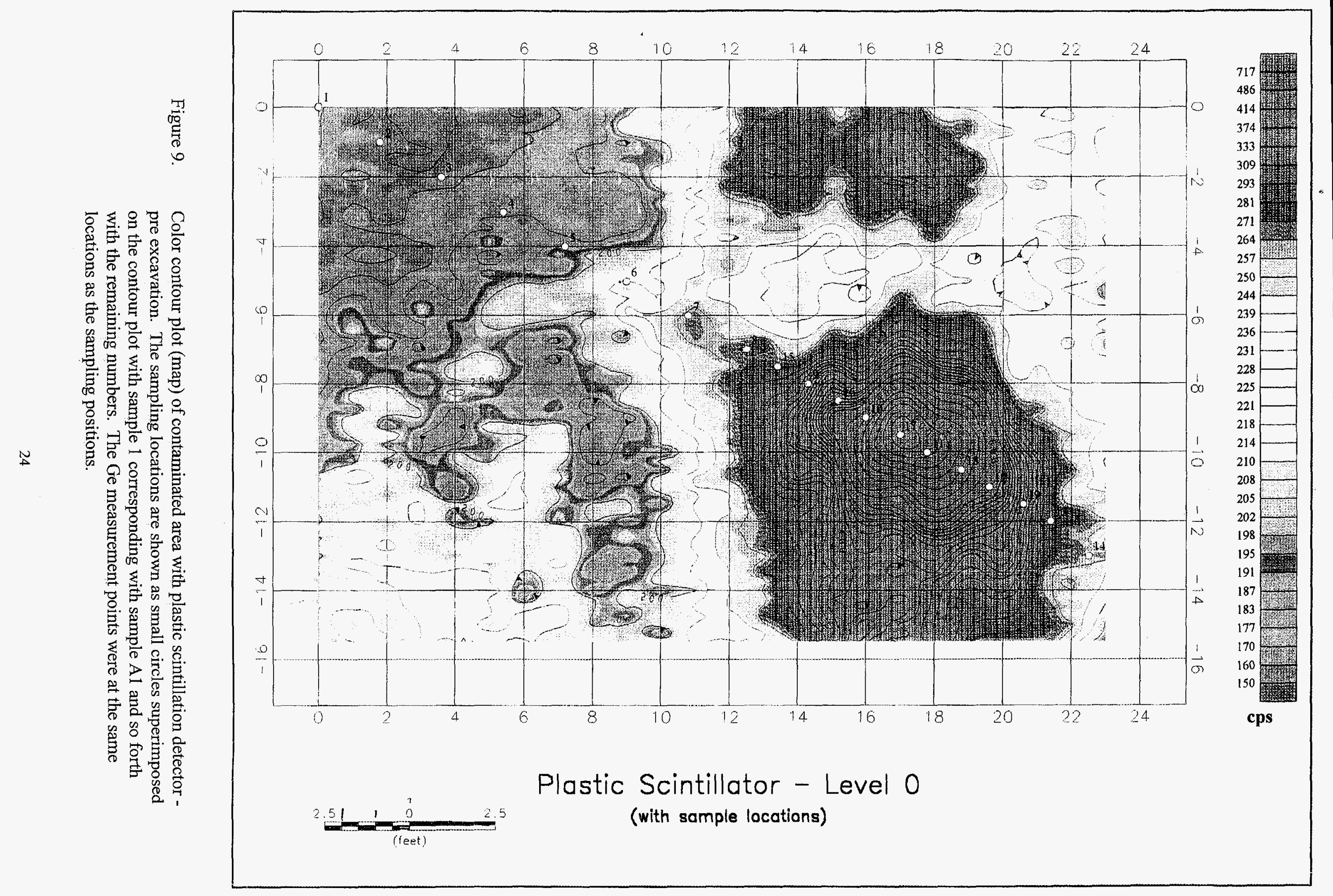




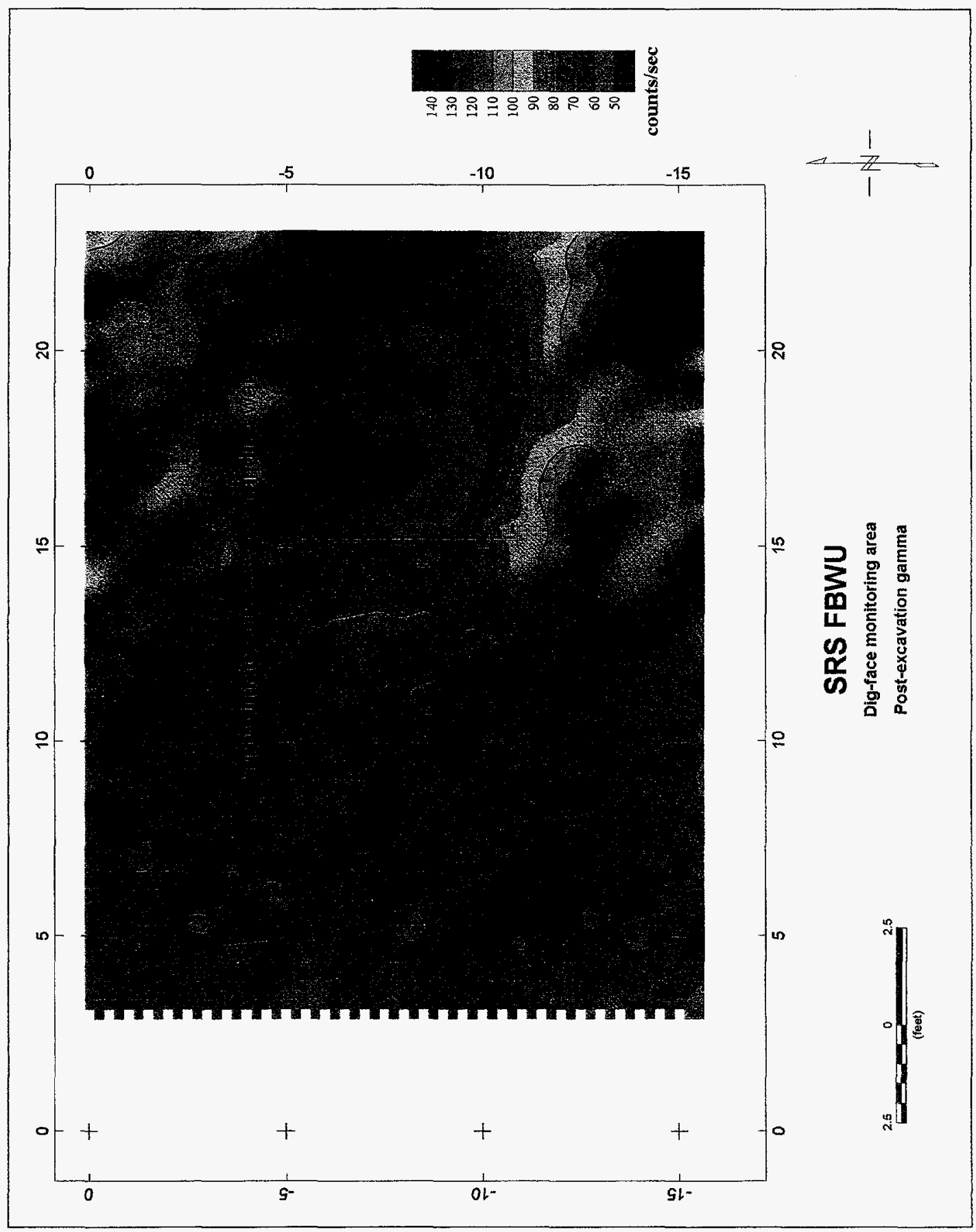

Figure 10. Color contour plot (map) of contaminated area with plastic scintillation detectorpost excavation. 
levels in the former hot spot locations are reduced by a factor of 10 to 20 . In the lower radiation field areas, radiation levels are reduced by a factor of $\sim 2$. The overall reduction in radiation levels is attributed to two factors: 1) the excavation removed a significant amount of ${ }^{137} \mathrm{Cs}$ contamination, and 2) the standing water from heavy rain caused increased $\gamma$-ray absorption reducing the radiation level accordingly. Although absorption effects are significant, even 10-20 $\mathrm{cm}\left(4-8^{\prime \prime}\right)$ of standing water cannot account for the observed reduction in radiation levels. Eight and $15 \mathrm{~cm}$ of standing water attenuate a $661 \mathrm{keV} \gamma$-ray signal $22 \%$ and $39 \%$, respectively. Since the reduction in radiation field is much greater than can be accounted for by the estimated range of depths of standing water, the reduction is attributed to removal of ${ }^{137} \mathrm{Cs}$ by excavation.

The previously noted decrease in radiation levels toward the $(0,0)$ corner of the data set is not observed following excavation. This could indicate that the ${ }^{137} \mathrm{Cs}$ has been removed over a large area to very low levels and that the residual radiation is due principally to natural background. The counts per second in this region are at or below our estimated background count rate for the plastic scintillation detector as stated in Sections 3.1 and 5.2.

\section{Conversion of data to ${ }^{137} \mathrm{Cs}$ concentrations}

There are four sets of data available to help define the ${ }^{137} \mathrm{Cs}$ concentrations at the site surveyed; a) the earlier pre cleanup $\mathrm{NaI}(\mathrm{T} 1)$ detector survey data; $b$ ) the plastic scintillation detector pre excavation continuous survey; c) the six pre excavation in situ Ge detector measurements; and d) the 19 soil samples that were analyzed by the Site laboratory. Data sets b) and c) can be converted to ${ }^{137} \mathrm{Cs}$ concentrations for any assumed source configuration. The laboratory analyses give the concentration based on a uniform distribution to a depth of $7.6 \mathrm{~cm}(3 ")$, the depth of the sample, and give no information about the concentration below that depth. [One could use the $\mathrm{NaI}(\mathrm{T} 1)$ and $\mathrm{Ge}$ detector data to calibrate the plastic scintillator data and thereby provide one set of results, but we have chosen to transform each set of data to $\mathrm{pCi} / \mathrm{g}$ and use the differences as a measure of the agreement and accuracy of the results.]

The maps in Figures 9 and 10 already identify the hot spots and the general features of the spatial distribution of the contaminations. However, if one wishes to define the area that needs to be cleaned up, the criterion for action is often specified in terms of the concentration, frequently in $\mathrm{pCi} / \mathrm{g}$. Therefore, it is necessary to convert the available data activity concentrations $(\mathrm{pCi} / \mathrm{g}$ ) with the necessary stipulation that the conversion factors are only valid for specified contamination distributions (i.e., horizontal extent and depth).

The results in $\mathrm{pCi} / \mathrm{g}$ from the earlier $\mathrm{NaI}(\mathrm{T} 1)$ detector measurements are shown in Figure 8 .

In order to use the data in Table 2 or 7 to convert the count rates in Figure 9 to possible ${ }^{137} \mathrm{Cs}$ activity concentrations, one must subtract a background count rate and assume horizontal and vertical contamination distributions for each location. If the soil-detector distance is not constant at the positions used in Tables $1-7$, this should also be taken into account. Because the correction is relatively small for variations in the plastic detector to ground distance, and the 
other uncertainty components are quite large $\sim 2$, correction for variations in the detector to ground height were neglected.

\subsection{Depth Distribution}

Some depth distribution information was obtained during the pre-work plan characterization conducted in May and June 1996. This information indicated that the majority of ${ }^{137} \mathrm{Cs}$ contamination was in the top $15 \mathrm{~cm}\left(6^{\prime \prime}\right)$ of soil. The ${ }^{137} \mathrm{Cs}$ measurement from an in situ $\mathrm{Ge}$ detector at position $\mathrm{A} 09$ detected the $32 \mathrm{keV} \mathrm{Ba} \mathrm{Kx}$ ray emitted by ${ }^{137} \mathrm{Cs}$. The count rates in the $\mathrm{K}_{\alpha} \mathrm{X}$-ray and $\gamma$-ray peaks were 1.38(9) and 23.33(24). The uncertainty in parenthesis is one estimated standard deviation. This ratio, equal to 0.059 , is statistically the same as the ratio for $120 \mathrm{~cm}$ diameter source uniform to $15 \mathrm{~cm}$ deep in Table 6 . This value indicates that at location A09 the ${ }^{137} \mathrm{Cs}$ is distributed well into the soil, probably to $\sim 15 \mathrm{~cm}\left(6^{\prime \prime}\right)$, but some of the contamination also lies near the surface otherwise the $\mathrm{K}_{\alpha} \mathrm{x}$-ray would not have been detected. Unfortunately, Ge measurements at other sampling locations were not saved to disk and the $\mathrm{Ba} \mathrm{K}$ $\mathrm{x}$ ray peak count rate was not measured at these other locations. Therefore, depth distribution information was not obtained at the other locations.

Therefore, from the pre-work plan characterization, the in situ Ge measurement at position A09, and the drop in radiation field from the post excavation map, the bulk of the ${ }^{137} \mathrm{Cs}$ contamination appears to have been in the top $15 \mathrm{~cm}$ of soil.

\subsection{Background for the Plastic Scintillation Detector}

From a comparison of the count rates in the plastic scintillator with the ${ }^{137} \mathrm{Cs}$ concentrations determined for several of the samples analyzed in the laboratory (specifically at A01-A06 in Figure 8), it was deduced that this background is $\sim 120$ counts $/ \mathrm{s}$. This compares to the measured count rates of 149 at position $\mathrm{A} 01$ and 144 at A02. The following data analysis has used this result. However, it should be pointed out that the in situ Ge detector spectrum taken at A01 does not agree with this result. These Ge detector data can be used to estimate the relative amounts of ${ }^{137} \mathrm{Cs},{ }^{40} \mathrm{~K},{ }^{228} \mathrm{Th}$, and possibly ${ }^{226} \mathrm{Ra}$ that are present at location A01. A consideration of the response of the plastic scintillator to the various $\gamma$ rays from these radionuclides and their daughters indicate that even at A01 more than $50 \%$ of the plastic scintillators counts appear to be from ${ }^{137} \mathrm{Cs}$, i.e., the background is at or less than 70 counts/s. If this lower background were used, the concentrations in Table 9 for the plastic scintillator would all increase by about $2 \mathrm{pCi} / \mathrm{g}$.

\subsection{Conversion for Plastic Scintillator Data}

It is reasonable to expect the depth profile of the ${ }^{137} \mathrm{Cs}$ contamination to vary with location in Figure 8, but lacking information in this matter, we have assumed the contamination is uniform to $15.2 \mathrm{~cm}$ (6 inches) everywhere. For example, it is reasonable to assume that depressions in the ground surface would allow longer contact with contaminated water than areas where 
contaminated water just flowed over the area. Longer contact could result in a build up of the contamination in this area and permit deeper penetration into the ground.

For the horizontal distribution, we have chosen to use the calibration factor in Table 7 for the $120-\mathrm{cm}$ diameter disk for all regions except near the four hot spots; that is 32.6 counts/s for 1.0 $\mathrm{pCi} / \mathrm{g}$ contamination level. Near the peaks of the hot spots this factor should be smaller, but the correct value is not known. We have arbitrarily chosen the value of 10.0 for sample positions A09 to A12. At the peak of the hot spot this value is probably less than 10.0 [e.g., a 10-cm diameter source distributed uniformly with depth to $15 \mathrm{~cm}\left(6^{\prime \prime}\right)$ has a calibration factor of $0.61 \mathrm{c} / \mathrm{s}$ per $1.0 \mathrm{pCi} / \mathrm{g}]$. On the sides of the peaks our modeling of uniform distributions is clearly not correct, but values between 10.0 and 32.6 might be reasonable.

With these parameters for the background count rate and the conversion factors, the map in Figure 9 could be remade in $\mathrm{pCi} / \mathrm{g}$. At the 19 positions A01-A19 in Figure 9, one has the results shown in Table 9. The values in this table have not been corrected for the difference between the soil-detector shield distance used in the modeling and those at which the measurements were made. The former distance is $15.2 \mathrm{~cm}$ and the latter range from 17 at A14 to $37 \mathrm{~cm}$ at A01. As shown in Appendix B, this correction can be large for small diameter sources, but this situation would only apply to the Table 9 data on the hot spot, and here the distances are near the modeled distance. At A01 where the difference in distances is large, we estimate from the Appendix B data the correction would increase the result by $30 \%$, but at A02 the correction is down to $20 \%$. These corrections have not been made. 
Table 9. $\quad{ }^{137} \mathrm{Cs}$ concentrations deduced from plastic scintillator data with background of 120 counts/s

\begin{tabular}{|c|c|c|c|}
\hline Position & Net counts/s & Conversion factor & $\begin{array}{c}\text { Concentration } \\
(\mathrm{pCi} / \mathrm{g})\end{array}$ \\
\hline $\mathrm{A} 01$ & 29 & 32.6 & 0.9 \\
\hline A02 & 24 & 32.6 & 0.7 \\
\hline A03 & 39 & 32.6 & 1.2 \\
\hline A04 & 56 & 32.6 & 1.7 \\
\hline A05 & 63 & 32.6 & 1.9 \\
\hline A06 & 91 & 25.0 & 3.6 \\
\hline A07 & 147 & 20.0 & 7.4 \\
\hline A08 & 124 & 20.0 & 6.2 \\
\hline A15 & 159 & 15.0 & 10.6 \\
\hline A09 & 252 & 10.0 & 25.2 \\
\hline A16 & 435 & 10.0 & 43.5 \\
\hline A10 & 802 & 10.0 & 80.2 \\
\hline A17 & 1354 & 10.0 & 135 \\
\hline Al1 & 1304 & 10.0 & 130 \\
\hline A18 & 869 & 10.0 & 86.9 \\
\hline A12 & 479 & 10.0 & 47.9 \\
\hline A19 & 269 & 20.0 & 13.5 \\
\hline $\mathrm{A} 13$ & 160 & 32.6 & 4.9 \\
\hline A14 & 138 & 32.6 & 4.2 \\
\hline
\end{tabular}




\subsection{Conversion for in situ Ge detector data}

With the same parameter decisions as discussed above in Sect. VC, the six $662-\mathrm{keV} \gamma$ ray peak count rates from the in situ measurements can be converted to ${ }^{137} \mathrm{Cs}$ contamination levels. These results are given in Table 10.

Table 10. $\quad{ }^{137} \mathrm{Cs}$ concentrations deduced from the in situ $\mathrm{Ge}$ detector data

\begin{tabular}{|l|l|l|l|}
\hline \multicolumn{1}{|c|}{ Position } & \multicolumn{1}{c|}{ Peak counts/s } & Conversion factor & Concentration $\mathbf{( p C i / g )}$ \\
\hline A01 & $0.260(17)$ & $8.2 \times 10^{-2}$ & 3.2 \\
\hline A09 & $1.008(33)$ & $8.2 \mathrm{~s} 10^{-2}$ & 12 \\
\hline A10 & $11.94(15)$ & $5 \times 10^{-2}$ & 240 \\
\hline & & & \\
\hline A11 & $23.33(24)$ & $4 \times 10^{-2}$ & 580 \\
\hline A12 & $5.42(9)$ & $6 \times 10^{-2}$ & 90 \\
\hline A13 & $1.18(4)$ & $8.2 \times 10^{-2}$ & 14 \\
\hline
\end{tabular}

\subsection{Comparison of ${ }^{137} \mathrm{Cs}$ Concentrations from Various Sets of Data}

The locations of the $\mathrm{NaI}(\mathrm{T} 1)$ measurements do not match those of the in situ Ge and laboratory samples, so they will be considered separately. The comparisons of the other three sets of values at positions A01-A19 are given in Table 11.

Table 11. Comparisons of ${ }^{137} \mathrm{Cs}$ concentrations deduced

\begin{tabular}{|l|l|l|l|}
\hline \multirow{2}{*}{ Position } & \multicolumn{2}{|c|}{${ }^{\mathbf{1 3 7}}$ Cs concentration (pCi/g) } \\
\cline { 2 - 4 } Plastic Scin. & Ge in situ & Sample in lab \\
\hline A01 & 0.9 & 3 & 1.8 \\
\hline A02 & 0.7 & & 1.6 \\
\hline A04 & 1.2 & & 2.9 \\
\hline & 1.7 & & 4.6 \\
\hline A05 & & & \\
\hline A06 & 1.9 & & 3.9 \\
\hline
\end{tabular}




\begin{tabular}{|c|c|c|c|}
\hline \multirow[b]{2}{*}{ Position } & \multicolumn{3}{|c|}{${ }^{137} \mathrm{Cs}$ concentration ( $\mathrm{pCi} / \mathrm{g}$ ) } \\
\hline & Plastic Scin. & Ge in situ & Sample in lab \\
\hline A07 & 7.4 & & 34.4 \\
\hline A08 & 6.2 & & 16.3 \\
\hline A15 & 10.6 & & 18.3 \\
\hline A09 & 25.2 & 12 & 15.7 \\
\hline A16 & 43.5 & & 314 \\
\hline $\mathrm{A} 10$ & 80.2 & 240 & 511 \\
\hline A17 & 135 & & 960 \\
\hline A11 & 130 & 580 & 382 \\
\hline A18 & 86.9 & & 252 \\
\hline A12 & 47.9 & 90 & $0.24^{b}$ \\
\hline A19 & 13.5 & & 48.8 \\
\hline A13 & 4.9 & 14 & 29.2 \\
\hline A14 & 4.2 & & 33.7 \\
\hline
\end{tabular}

The main conclusion from the data in Table 11 is that the various procedures and detectors see different sources. Because the plastic detector averages over a large area $\left(-2800 \mathrm{~cm}^{2}\right.$ at FWHM) while the soil samples cover a small area $\left(\sim 80 \mathrm{~cm}^{2}\right)$, the sampling results in the last column show much wider variations in the concentration.

In the low-activity region (i.e., A01 to A05) the contamination is relatively uniformly distributed as illustrated in Figure 9. It is in this region that the activity concentrations measured by the different methods (plastic scintillator, Ge spectrometer, and samples) should agree within the measurement uncertainty. Unfortunately, the results from the plastic scintillation detector are

${ }^{b}$ We believe the sample result for position A12 is suspect or the variation in spatial contamination is more extreme than can be resolved by the map obtained with the plastic detector (e.g., see discussion of spatial resolution in Section IIIA). 
approximately half of the sample results. This difference is probably due to several factors but we believe it is primarily due to the use of a background of $120 \mathrm{c} / \mathrm{s}$ instead of a lower value of $\sim 70 \mathrm{c} / \mathrm{s}$ as suggested by the relative contributions of the natural radionuclide activities detected at location A01 with the Ge spectrometer measurement (see Section VB). Use of a background of $70 \mathrm{c} / \mathrm{s}$ would result in activity concentrations statistically equal to or greater than those from the samples taken at positions A01 through A05. The plastic detector results at $\mathrm{A} 01$ of $2.45 \mathrm{pCi} / \mathrm{g}$ would then be in approximate agreement with the $\mathrm{Ge}$ result of $3 \mathrm{pCi} / \mathrm{g}$ at position $\mathrm{A} 01$. In a region of uniform contamination in horizontal extent small differences in the detector ground distance will have a small change in the measured activity concentration and so this correction has not been made.

The Ge result at position $\mathrm{A} 01$ is based upon an activity concentration that is uniform to $15 \mathrm{~cm}$ depth. It is also based upon a soil density of $1.5 \mathrm{~g} / \mathrm{cm}^{3}$ and a moisture content of $20 \%$. If the soil density under field conditions is closer to 2.0 due to its moisture content, the $\mathrm{Ge}$ spectrometer measured activity concentrations of $3 \mathrm{pCi} / \mathrm{g}$ would become $2.2 \mathrm{pCi} / \mathrm{g}$ in agreement $( \pm 25 \%)$ with the laboratory result of $1.8 \mathrm{pCi} / \mathrm{g}$.

In the region of higher activity and rapidly changing count rate (i.e., A09 to A13) the background is a smaller contributor to the plastic detector's gross count rate. In this region the large field of view of the plastic detector extends over a large range of count rates with the recorded counts tending to be an average of the high and low activity regions viewed. In traversing the hot spot this averaging effect will frequently result in a lower count rate than if the hot spot extended over the entire field of view of the plastic detector as observed in Table 11. Since the field of view of the Ge $\gamma$-ray spectrometer is much less than the plastic, this averaging effect will be less pronounced as seen in Table 11. Therefore, the Ge $\gamma$-ray spectrometer results are expected to be in better agreement with the sample results than those of the plastic scintillation measurements.

In Figure 8 are shown some of the ${ }^{137} \mathrm{Cs}$ activity concentrations from the Initial Site Characterization sampling results. Because these measurements are at different positions than those of the present investigation, they cannot be compared directly. However, the map of count rates from the present study are in general agreement with those from the Initial Site Characterization. Further, by comparisons with like count rate locations the present activity concentrations appear to be in agreement (within a factor of $\sim 2$ ) of the activity concentrations measured previously.

\subsection{Uncertainty Components}

Because a realistic estimate of the total uncertainty through propagation of all uncertainty components is not practical at the present time, a full propagation of uncertainties has not been performed. However, some effort should and has been made to estimate reasonable ranges for each uncertainty component and for the total uncertainty. All uncertainty components are one estimated standard deviation. Below is the result of an effort to so define the more obvious uncertainties primarily associated with the plastic scintillation detector. 
1. Statistical Uncertainty. The percent uncertainties in the background subtracted net count rates for the plastic scintillator data are not significant contributors to the total uncertainty in the regions at and near the hot spots (e.g., for $1000 \mathrm{c} / \mathrm{s}$ and $120 \mathrm{c} / \mathrm{s}$ background the net count rate is $880 \pm 34$ or $\pm 3.9 \%$. However, in the region of low activity concentration, this uncertainty in the net count rate of the plastic scintillator data is significant. For example, for a background of $120 \mathrm{c} / \mathrm{s}$ and a measured gross count rate at position A01 of $149 \mathrm{c} / \mathrm{s}$ the net count rate is propagated to be $29 \pm 16$ or $55 \%$. The net peak areas for the $661-\mathrm{keV}$ peak measured with the Ge $\gamma$-ray spectrometer is $<10 \%$ for all six locations measured.

2. Horizontal Extent of Contamination. Before the conversion factor from $\mathrm{c} / \mathrm{s}$ to $\mathrm{pCi} / \mathrm{g}$ ) can be applied, either the extent of the contamination must fill the field-ofview of the detector or the size and location of the contamination must be well known and carefully modeled. A review of Tables 2 and 4 show that a factor of 2 to 10 error can result from estimating a contaminated area to be $10-\mathrm{cm}$ in dia. when in fact it is actually $120 \mathrm{~cm}$ in diameter or vice versa. Symmetry in alignment of the contamination distribution with that of the detector is also an important factor if large errors in reported activity concentrations are to be avoided. Alternatively, the reported results could be based on a space averaging calculation covering a specified area that would need to be accepted by the cleanup requirements and regulations.

3. Distribution with Depth. By reviewing Tables 2, and 4, one can see that a factor of 2 error can easily be made by wrongly estimating the depth distribution of the contamination. Hence, a factor of 4 to 20 can result from wrongly estimating the full distribution of the contamination.

4. Soil Density and Moisture. Typical soil densities range from $\sim 1.3 \mathrm{~g} / \mathrm{cm}^{3}$ to $\sim 2.0$ $\mathrm{cm} / \mathrm{g}^{3}$. This difference for a $15-\mathrm{cm}$ uniform depth distribution can cause as much as a $40 \%$ error.

5. Soil composition. Soil composition varies significantly but at $661 \mathrm{keV}$ the difference in soil composition has a small effect on attenuation. However, at low energies (the $\mathrm{Ba} \mathrm{Kx}$-rays are at 32 and $36 \mathrm{keV}$ ) these variances can cause large errors (as much as $\sim 30 \%$ ).

6. Model versus measured comparisons indicate the model values may be in error by 5 to $20 \%$ depending upon the energy of the photon, detector type and the complexity of the geometry modeled. Detector efficiencies for gamma rays $>150$ $\mathrm{keV}$ can usually be modeled with a resulting uncertainty of $<5 \%$. 
Comparisons of field measurements with laboratory results requires that the moisture content and density of the soil be known and that each analysis technique report results under the same conditions of moisture content and density.

From the above, the following observations can be made:

1. The percent total uncertainty in the activity concentrations in Table 11 for the plastic scintillation data can be of 300 to $400 \%$ for the low-activity concentrations measured at positions A01 through A05 where the horizontal extent is known and can be $500 \%$ for the high activity concentrations where neither horizontal extent or depth distribution is well known.

2. The percent total uncertainty in the activity concentrations in Table 11 for the Ge spectrometer can be $200 \%$ for the low concentrations measured at A01 through $\mathrm{A} 05$ and be $400 \%$ for the high activity concentrations.

3. Under ideal conditions of uniform distribution in horizontal extent and known and even depth distribution in situ Ge spectrometry at a one meter height can measure activity concentrations to $\pm 8 \%$.

\section{Discussion}

A high density of in situ radiation measurements like those collected at FBWU 643-11G with the plastic scintillator provide a sound basis for evaluating the spatial distribution of radioactive contamination. In particular, high density measurements can be used to distinguish between concentrated point sources and uniformly distributed sources. Four distinct hot spots were identified at FBWU. The remainder of the site contained low-level contamination decreasing gradually to the north. In many cases this semi-quantitative information alone can be used to efficiently focus a soil clean-up operation. Further development of the "point source" or system response concepts presented above is needed to more accurately convert raw count rates to activity concentrations over regions of rapidly changing count rates. Verification of such new methods may require comparison of results with samples collected on a finely divided grid similar to the in situ measurements, i.e., about 1 sample per $\sim 1,000 \mathrm{~cm}^{2}\left(1 \mathrm{ft}^{2}\right)$.

Quantitative estimates of radionuclide concentration have been shown to depend on both the spatial and depth distribution of the contaminant. The density of the soil and its moisture content are also important if quantitative results are to be reported in $\mathrm{pCi} / \mathrm{g}$. Whereas dig-face monitoring provides a superior basis for determining spatial distribution, depth distribution remains problematic. Radiation field maps generated by sensors like the plastic scintillator contain little information from which depth distribution can be ascertained. At FBWU, this translated into as much as a factor of 10 uncertainty in concentration estimates corresponding to the difference between $\mathrm{a} \sim 1 \mathrm{~cm}(.03 \mathrm{ft})$ deep distribution versus a $15 \mathrm{~cm}(0.5 \mathrm{ft})$ deep distribution. These estimates assumed that the contamination was confined to a finite layer that 
commenced immediately at the soil surface. The potential for a thin layer of clean soil overlying the contamination layer introduces an additional source of ambiguity.

It is important to note that traditional sampling methods also suffer from uncertainties regarding the depth distribution of radionuclide contaminants. For example, the $7.6 \mathrm{~cm}(3 ")$ deep sample cores that were collected at FBWU give an average over the $7.6 \mathrm{~cm}$. The ${ }^{137} \mathrm{Cs}$ may in fact have been confined to a thin layer near the top, bottom, or middle of the core. In this case, the reported sample result does not give the concentration of ${ }^{137} \mathrm{Cs}$ in the actual contamination layer but an average of the contaminated layer plus any clean soil layers surrounding it. For these reasons, measurements in units of $\gamma / \mathrm{s} / \mathrm{cm}^{2}$ at the surface of the ground may be more meaningful. Finally, since the activity concentrations measured with the Ge spectrometer were taken under well-defined experimental conditions and the field-of-view of the Ge spectrometry was much smaller than for the plastic scintillation detector the measured activity concentrations should be more accurate assuming the assumptions regarding depth distribution of the contaminant are valid. For these reasons the in situ Ge $\gamma$-ray spectrometer results are also expected to be in better agreement with the sample results than those of the plastic scintillation detection.

As noted in Section 5.5 it is possible that the activity concentration results from the plastic scintillation detector, Ge spectrometer, and samples would be in good agreement in the region of uniform horizontal distribution if the plastic detector background had been measured directly and the soil moisture and density was measured. These are necessary measurements if quantitative activity concentrations are to be reported. Unfortunately, no provision was made to measure the background of the plastic scintillation detector at the SRS. Soil moisture and density needs to be measured in any future in situ measurements.

In the regions of rapidly changing count rates it may be necessary to either lower the plastic scintillation detector close to the ground at several locations to obtain a count rate over a smaller area ( same foot print as the detector, $30 \mathrm{~cm} \times 30 \mathrm{~cm}$ ) that can be converted to $\mathrm{pCi} / \mathrm{g}$ or to accept activity concentrations that are a spatial average over the detector's full field of view. Alternatively, the Ge $\gamma$-ray spectrometer with its more limited field of view could be used to measure activity concentration at a number of key locations and used to convert the map of count rates to activity concentration, $\mathrm{pCi} / \mathrm{g}$. This alternative has the advantage of identifying and quantifying all the radionuclides present but the disadvantage of consuming time and adding costs.

In conclusion, it appears that the Dig Face Characterization System provides valuable qualitative maps and semiquantitative activity concentrations and has the potential to provide quantitative information that can provide invaluable guidance to the cleanup crew. In this way the cleanup crew can make remediation decisions in a timely and efficient manner. When a fully developed protocol has been successfully tested, the need for sampling and off-site characterization could be reduced to only that required by regulation to verify final release criteria. Because in situ characterization results in $100 \%$ coverage of the site at a fraction of the cost of laboratory analyses, the Dig Face Characterization System will also significantly reduce the need for rework 
of a site that was believed to have been remediated but remained with areas above the cleanup criteria.

\section{Quality Program}

The measurements carried out during this study followed good standard practices for ionizing radiation measurements as identified in text books on radiation measurements ${ }^{11}$ and more specifically in ANSI standards N42.14 (Ge spectrometry) ${ }^{12}$ and N42.12 [NaI(Tl) gross counting $]^{13}$. The modeling results from the CYLTRAN code compared with measurements of specially prepared large-area surface sources provided validity to the modeling results for the geometry modeled. The large-area $1.2 \mathrm{~m} \mathrm{x} 1.2 \mathrm{~m}$ sources of ${ }^{137} \mathrm{Cs}$ were constructed by Analytics ${ }^{9}$ following techniques that assure traceability to the National Institute of Standards and Technology (NIST).

\section{References}

1. "Technical Oversight of Sampling for the N-Area ford Building Waste Unit (643-11G) and Fire Department Hose Training Facility (904-113G)", Report No. WSRC-RP-96-856, Rev. D (1996).

2. "Removal Site Evaluation Report for Soil Removal at the Ford Building Waste Unit (643-11N), Report No. WSRC-RP-96-850, Rev. 1 (1996).

3. G. A. Williams, M. B. Cooper, L. J. Martin and J. Harries, "Characterization of Particulate Plutonium Contamination at the Former British Nuclear Test Site at Maralinga, South Australia,"In "A Summary Report of the Second Research Coordination Meeting on Site Characterization Techniques Used in Environmental Restoration," held at CIEMAT Facility, Madrid, Spain, Nov. 3-7, 1997.

4. A portable dewar type for Ge spectrometer that is a product of Canberra Industries.

5. R. J. Gehrke, E. W. Killian, L. V. East, J. M. Hoggan, S. G. Goodwin, and G. D. McLaughlin, "A Portable Photon Analysis Spectrometer for Assay of X- and Gamma-Ray Emitting Radionuclides", accepted for publication in the Journal of Radioanalytical and Nuclear Chemistry (1998).

6. N. E. Josten, R. J. Gehrke, and M. V. Carpenter, "Dig-face Monitoring during Excavation of a Radioactive Plume at Mound Laboratory, Ohio", Report no. INEL-95/0633 (December 1995).

7. H. L. Beck, J. DeCampo and C. Gogolak, "In situ Ge(Li) and NaI(T1) Gamma-Ray Spectrometry", Report HASL-258 (U. S. Department of Energy, Environmental Measurements Laboratory, New York), 1972. 
8. J. A. Halblieb, R. P. Kensek, and T. A. Mehlhorn, Nuclear Science and Engineering, 92 338 (1986); Sandia National Laboratory, SAND-84-0573, and SAND91-1634 (Revision of SAND84-0573).

9. Analytics, Inc., 1380 Seaboard Industial Blvd., Atlanta, GA 30318.

10. E. Browne and R. B. Firestone, "Table of Radioactive Isotopes" (John Wiley and Sons, New York) 1986.

11. K. Debertin and R. G. Helmer, Gamma- and x-Ray Spectrometry with Semiconductor Detectors, North-Holland publishing Co., Elsevier Science Publishers, Amsterdam, Oxford, New York, Tokoyo (1988).

12. American National Standard, "Calibration and Use of Ge Spectrometers for the Measurement of Gamma-Ray Emission Rates of Radionuclides", ANSI-N42.14-1991.

13. American National Standard, "Calibration and Usage of Alpha/Beta Proportional Counters," ANSI-N42.25-1997. 
APPENDIX A

A-1 


\title{
APPENDIX A
}

\section{SETTING THE LOWER-LEVEL DISCRIMINATOR}

\author{
OF A PLASTIC SCINTILLATION DETECTOR
}

\section{Introduction}

The plastic scintillation detector designed for in-situ assay consists of a 12 " $\mathrm{x} 12$ " $\mathrm{x} 1.5$ " plastic scintillator with digital output in RS232 format for wirless communication with a Graphics Workstation. The detector/pulse processing circuitry is mounted as an integral assembly in a totally enclosed aluminum case with side shielding of 2 " thick lead bricks surrounding all four

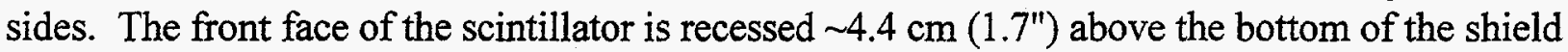
to provide a better-defined viewing angle of the soil 6 " below the bottom of the case. The four inch height of the lead bricks surrounding the plastic scintillator provide shadow shielding even from radiation emitted from the walls of an excavation. This entire assembly with detector/electronics, shielding, and case weigh $\sim 230 \mathrm{lbs}$ and couple to the Dig-Face Trolley by two retaining pins.

\section{Setting the Lower-Level Discriminator} With a Modified NOMAD Portable Multichannel Analyzer (MCA).

A portable EG\&G Ortec NOMAD multichannel analyzer is modified so that amplified pulses from the plastic scintillator can be fed directly into the analog-to-digital $(\mathrm{ADC})$ input. A gate and delay generator is used to shape and delay the output pulse from the plastic detector lowerlevel discriminator output so that it can be used to gate the MCA on only when an amplifier output pulse is above the lower-level-discriminator. The amplifier output pulse is also delayed so that the amplifier pulse and gate pulse arrive at the MCA at the same time. Several RG62 coaxial cables with BNC connectors on each end are used to connect the BNC output of the amplifier to a delay box which in turn is connected to the $\mathrm{ADC}$ input. Sources of $\sim 10 \mu \mathrm{Ci}{ }^{137} \mathrm{Cs}$ and ${ }^{60} \mathrm{Co}$ source are needed to perform the calibration. The amplifier and gate pulse delays and the width of the gate pulse are monitored during adjustment with an Oscilloscope so that the amplified pulse is contained in time by the gate pulse.

\subsection{Power Up the NOMAD-modified Multichannel Analyzer:}

1. If not connected, connect the parallel interface connectors to the NOMAD and to the back of the PC (this is the $\sim 10$ " long ribbon-like cable with connectors on each end. Connect the twisted pair (blue and black wires with banana plug) to the NOMAD +5 volt connector. Verify that the shut down (SD) BNC connector on the NOMAD has a terminator $(100 \mathrm{ohm})$ connected to it. 
2. Power up the NOMAD multichannel analyzer (MCA).

3. Power up the associated NOMAD PC.

Warning! The NOMAD MUST be powered up before the PC or the PC will not recognize the presence of the NOMAD.

4. Hit the return key when the time and date are displayed to keep them as is or enter a new time and date.

5. Double click the mouse on the Program Manager icon.

6. Find the PINS Applications Window and double click on the MAESTRO icon.

7. Verify that the MAESTRO-092x-P09 full-window display is being viewed.

8. Click on the Acquire pull down menu and click on Presets. Enter 120 seconds in the Live Time box. The "Acquire" pull-down menu allows the operator to set a count time, start and stop acquisition of a spectrum, clear a previous spectrum, and transfer a spectrum in the MCB (NOMAD) to the Buffer (PC). If the "Acquire" pull-down menu is not active there may be a problem with the communication between the PC and the NOMAD (e.g., parallel interface not properly connected or the 5 volt wire from the parallel interface not plugged into the NOMAD 5 volt power source).

The value of 120 seconds may be lengthened or shortened depending on the statistics required and the activity of the source and the geometry counted.

9. On the right-hand side of the screen is a box labeled "Display." Click in sequence on the circles labeled MCB and Full. In the same "Display" box click on the up or down arrows affecting the vertical and horizontal displays until vertical is in Log display and horizontal is 8192 . This allows various display options including many linear displays of counts and the number of channels that are viewed.

Comment: These adjustments to the display will be changed in the process of acquiring and evaluating data. For example, the linear scale may provide better resolution of the spectral counts and therefore be more desireable for setting the discriminator levels. The horizontal display indicates the number of channels displayed with 8192 channels being the full spectrum.

10. Using an RG62 coaxial cable (93ohm impediance) connect the BNC connector mounted at the top of the electronics board of the plastic scintillation detector assembly to the amplifier output connector (labeled AMP OUT) on the NOMAD 
multichannel analyzer. With the MCA modified this allows a pulse to be fed directly into the input of the ADC.

\subsection{Acquiring a Spectrum to Measure the Energy Scale:}

1. Power up the plastic detector by turning on the line power switch mounted near the top of the electronics boards.

2. Place a point cesium-137 $\left({ }^{137} \mathrm{Cs}\right)$ source under the approximate center of the detector. If the source is $\sim 10 \mu \mathrm{Ci}$, have the source about $6^{\prime \prime}$ to $8^{\prime \prime}$ below the detector window. If the source is $\sim 1 \mu \mathrm{Ci}$, have the source about $2 "$ to 3 " below the detector array. In any case the total count rate should be $>50 \mathrm{c} / \mathrm{s}$ and not exceed $\sim 2000$ counts/second.

3. Wait for at least 15 minutes for the instrument to warm up and stabilize.

4. Check that step 9 in the previous section has been performed.

5. Pull down the Services menu and click on "Job Control." Go to the directory c:Imaestro by clicking on [--] if it is not already displayed. At $c: \backslash$ find the directory [maestro] and click on it; then click on off.job and "Run" to exit this pull down menu.. This allows the operator to acquire spectra in the singles mode with the analog-to-digital (ADC) converter gate disconnected.

6. On the right-hand side of the screen is a box labeled "Display." Click the circle labeled MCB.

Note: When the off.job command under the "job Control" was clicked the display automatically switched to buffer display.

7. Pull down the menu under "Acquire."

8. Click on "Presets."

9. Enter in the Live Time box 600 seconds or a longer time and click on Ok.

10. Pull down the menu under "Acquire."

11. Click on "start."

12. Spectral data should be acquiring and being stored with a spectrum building in the display mode. If no spectral data is observed being stored, check that the entire spectrum (i.e., 8192 channels) is displayed and the display is either in log or 64 
counts full scale. If still no data being acquired and stored, get help or check the signal at the Amplifier Out connector of the NOMAD with an oscilloscope. The maximum energy for the spectrum should be 2,000 to $3,000 \mathrm{keV}$ or 10 volts.

13. Upon completion of the spectrum acquisition click on "Acquire" pull down menu and click on "Copy MCB > Buffer." This moves the spectrum out of the MCB (in the NOMAD) and into the buffer where it can be analyzed, and saved to disk.

Warning: If a spectrum is not copied to the Buffer, the previous spectrum that was copied to the Buffer will be analyzed and saved. This is a problem since the wrong data has been kept and analyzed.

15. Create a region-of-interest (ROI) with the curser by setting the beginning and ending channels that encompass the Compton peak at $460 \mathrm{keV}$. This is done with the ROI pull-down menu locating the beginning and ending channels with the curser and entering them as the ROI. It will be necessary to expand this spectral region using the linear display and expand the channel region to display 256 or 512 channels. The Compton peak is not a strong, well resolved peak but rather a subtle rise in the spectrum about $25 \%$ below the maximium energy due to pulses from the source. Use the "Calculate" pull-down menu to calculate the peak position in channels and record it in a log book.

15. Before saving the acquired spectrum it is suggested that the user create a directory for these spectra using the MD DOS command. For instructional purpose assume that the created directory is called PL_CALIB and is a subdirectory of SPECTRA.

16. To save the spectrum just acquired and moved to the buffer, click on the "file" pull down menu and then click on "save as." The SAVE.CHN File header of the window will be displayed. Click on [--] until c:l is displayed just below the SAVE.CHN File header. Now click on the directory [spectra] and then the directory [pl_calib]. The path c:Ispectralpl_calib should be displayed below the SAVE.CHN File header. Now click on the box below in this window where the file name for the spectrum is to be entered. Use the following identification code for the file name: PLxxyyzz, where PL is for the plastic scintillation detector, $\mathrm{xx}$ is the month, yy is the day and $z z$ is the count sequence. Alternatively, click on the $[-a-]$ and save the spectrum to a diskette in the " $a$ " drive.

17. Now repeat steps 1 through 16 with a cobalt- $60\left({ }^{60} \mathrm{Co}\right)$ source and find its Compton peak at $1025 \mathrm{keV}$.

18. From the two Compton peak positions and their associated energies, calculate the energy scale equation including the gain and intercept. Using this equation determine the channel number equivalent to $150 \mathrm{keV}$. 


\section{Procedure to Set the Single Channel Analyzer Windows}

A radioactive source of ${ }^{137} \mathrm{Cs},{ }^{60} \mathrm{Co}$ or other source with a gamma ray above $150 \mathrm{keV}$ will now be used to set the lower-level discrimninator. To do this the MCA must be gated "on" only when a pulse is above the lower-level discriminator (to be set above $150 \mathrm{keV}$ ) as described below.

1. Pull down the Services menu and click on "Job Control." Go to the directory c:lmaestro by clicking on [--] if it is not already displayed. At c:l find the directory [maestro] and click on it; then click on coinc.job and "Run" to exit this pull down menu. This activates the coincidence gate. Only when a coincidence gate pulse is present at the time an amplifier pulse is at the input to the $\mathrm{ADC}$ will the amplifier pulse be digitized and stored.

2. Connect the black lead of a BNC cable with clip leads on one end to the center wire on the lower discriminator output at the back of the plastic detector assembly display module (this is the ground lead), and connect the red lead of the BNC cable with clip leads on the other wire labeled on the discriminator output on the back of the display module. Connect the other end of the cable to the input of the Gate and Delay Generator. The output of the Gate and Delay Generator is connected with a RG62 cable with female BNC connecter ends to Channel 1 of an oscilloscope. Be sure that the width of the Gate and Delay Generator is fully open (as wide as it will go). The oscilloscope should be set for the $\mathrm{x}$-axis to have $\sim 5$ to 10 microseconds per $\mathrm{cm}$ division and the $\mathrm{y}$-axis set to have $\sim 1$ volt per $\mathrm{cm}$ division. This pulse should be set to trigger the start of a scope sweep.

This allows the operator to acquire spectra in which only pulses from the discriminator output that are in coincidence with amplifier pulses are input to the $\mathrm{ADC}$ and stored.

3. With a RG62 cable connect the amplifier output of the plastic scintillation detector to the input of the Delay module and the output of the Delay module channel 2 of the oscilloscope.

4. Adjust the delay of the Delay module so that the channel 2 amplifier pulse is within the time range of the channel 1 square pulse.

5. Now connect the cable on channel 1 of the scope to the BNC Gate Input of the NOMAD, and channel 2 to the Amp Out BNC on the NOMAD.

6. On the right-hand side of the screen is a box labeled "Display." Click the circle labeled MCB.

7. Click on the Acquire pull down menu and click on Presets. Enter 600 seconds in the Live Time box. The value of 600 seconds may be lengthened or shortened 
depending on the statistics required and the activity of the source and the geometry counted.

8. Click on the Acquire pull down menu and click on "Start."

9. In the "gated" coincidence mode the only portion of the spectrum to be observed will be those counts that are above the discriminator set at $150 \mathrm{keV}$ in the last step of the previous section. Adjust the lower-level discriminator potentiometer to allow only pulses $>150 \mathrm{keV}$ to be counted.

10. Verify that no counts are being recorded below this channel.

14. Upon completion of the spectrum acquisition click on "Acquire" pull down menu and click on "Copy MCB > Buffer." This moves the spectrum out of the MCB (in the NOMAD) and into the buffer (in the PC) where it can be analyzed, and saved to disk.

16. To save the spectrum just acquired and moved to the buffer, click on the "file" pull down menu and then click on "save as." The SAVE.CHN File header of the window will be displayed. Click on [--] until c: $\backslash$ is displayed just below the SAVE.CHN File header. Now click on the directory [spectra] and then the directory [PL_CALIB]. Now c:lspectralPL_CALIB should be displayed below the SAVE.CHN File header. Now click on the box below in this window where the file name for the spectrum is to be entered. Use the following identification code for the file name: PLxxyyzz, where PL is for the plastic detector, $\mathrm{xx}$ is the month, yy is the day and $\mathrm{zz}$ is the count sequence. Alternatively, click on the [-a-] and save the spectrum to a diskette in the "a" drive.

17. Disconnect the BNC cables from the plastic detector's amplifier out connector and remove the probes from the wires at the output of the SCA.

18. Be sure to put the cover on the plastic detector making sure to leave the power-on switch in the "on" position if the detector is to be used in the field coupled to the Dig-Face platform and the output is to be sent by wireless communication using RS232 protocol. 
APPENDIX B

B-1 


\section{APPENDIX B}

\section{MONTE CARLO MODELING WITH CYLTRAN}

For the two detectors considered here, we have used the Monte Carlo electron and photon transport code CYLTRAN to model the detector response ${ }^{8}$. We have used this code with excellent success for many years for modeling of the response of $\mathrm{Ge}$ semiconductor detectors and $\mathrm{NaI}(\mathrm{Tl})$ scintillation detectors.

As background, it is useful to comment on what the Monte Carlo code provides and its limitations. For each specific calculation one provides as input two files of information. One is a file of information (i.e., a list of cross sections) on how electrons and photons (i.e., $\gamma$ rays and $x$ rays) interact with the different chemical elements that are present. The second file describes the physical geometry of the source, detector, and other materials as well as the $\gamma$-ray energy, the energy bins (called channels in an measured spectrum) in which the events are tallied/scored for the energy lost in the detector volume, and the number of photons to be emitted.

The code tracks each $\gamma$ ray as it travels through space and interacts with atoms in the various materials present. The electrons and secondary photons produced in these interactions are also tracked until all of their energy has been dissipated in the various materials or escaped out of the physical space included in the model.

For interactions in the detector volume, the code produces a tally of the number of events in each energy bin; that is, it provides an energy-loss spectrum. Since a measurement system does not directly measure the energy deposited in the detector, the calculated spectrum will differ to some extent from a measured spectrum even if the modeling is done without any approximations or errors. For a Ge semiconductor detector, which has a very linear response (i.e., the amplitude of the signal from the detector is proportional to the energy deposited) and very good energy resolution (i.e., any observed peaks are very narrow), the differences will often be very small. In contrast, a plastic scintillator has very poor energy resolution, so any peaks that occur in the Monte Carlo calculated spectrum will be smeared out and only marginally recognizable in the corresponding measured spectrum.

The CYLTRAN code used for this work requires that the geometry be axially symmetric, that is, each piece is either a right circular cylinder and annulus. Therefore, rectangular objects, such as the plastic scintillator, must be approximated as circular objects.

The geometrical description of the source-detector system for CYLTRAN can be as detailed as one wishes, as long as it has axial/cylindrical symmetry. For the three types of detectors discussed here, each geometrical description includes the following: 
the sensitive volume of the detector, the mounting materials around the detector, the entrance window or cover over the front of the detector, the shielding to reduce the response to photons from locations other than the ground below the detector,

the air between the source and detector, and the soil.

The peak efficiency, $\mathrm{G}_{\mathrm{p}}$, is simply the ratio of the peak counts to the photons emitted and it will depend on the photon energy and the source-detector geometry. There has been no attempt to generate a whole efficiency curve (i.e., $G_{p}$ vs photon energy over an extended energy range.)

\section{A. Modeling results for plastic scintillator}

A large number of calculations have been made with the CYLTRAN Monte Carlo photon and electron transport code in order determine the energy-loss spectra of the plastic scintillator for different source-detector geometries. As the photon and electron energy is deposited in the scintillator, it is converted to light and a portion of the light exits from the scintillator and interacts in the associated photomultiplier to produce an electronic pulse. The process of producing the light and the electronic pulse are not modeled. Therefore, in using these modeling results we are assuming that for our purposes the calculated energy-loss spectrum is equivalent to the electronic pulse that the detector system finally counts.

Since this code uses only geometries with axial symmetry, this $30.5 \mathrm{~cm} \times 30.5 \mathrm{~cm}$ (12" x 12") detector was modeled as a circular detector of the same area. Similarly, all of the sources were modeled as circular disks. The soil that was included in some of the calculations had the following elemental composition by weight: $58.8 \% \mathrm{O}, 28.7 \% \mathrm{Si}, 6.5 \% \mathrm{Al}, 2.8 \% \mathrm{Fe}, 2.0 \% \mathrm{H}$, and $1.1 \%$ C. This composition is $20 \%$ by weight water.

The energy-loss spectra have been analyzed for an electronic cutoff of both 50 and $150 \mathrm{keV}$. Only the data for a cutoff of $150 \mathrm{keV}$ are presented here since that more nearly represents the operation of this system (see Appendix A).

The fraction of the $662-\mathrm{keV} \gamma$ rays emitted from a disk source that deposit more than $150 \mathrm{KeV}$ in the scintillator are given in the Table 2 of the text for sources of different diameters and for various depths in the soil. This is the basic information used in the conversion of the observed count rates to contamination levels in the text, however, the soil-detector distance is $23 \mathrm{~cm}$ (9.06") whereas the reference distance for the Savannah River scans was $19.7 \mathrm{~cm}(7.75 ")$ (see Table B-1 for influence of the change in this distance).

The influence of the soil-detector distance is shown in Table B-2 which gives the fraction of the emitted $662-\mathrm{keV} \gamma$ rays that deposited more than $150 \mathrm{keV}$ of energy in the plastic scintillator. This shows the range in the calibration factor as the system scans over rough ground. 
Table B-1

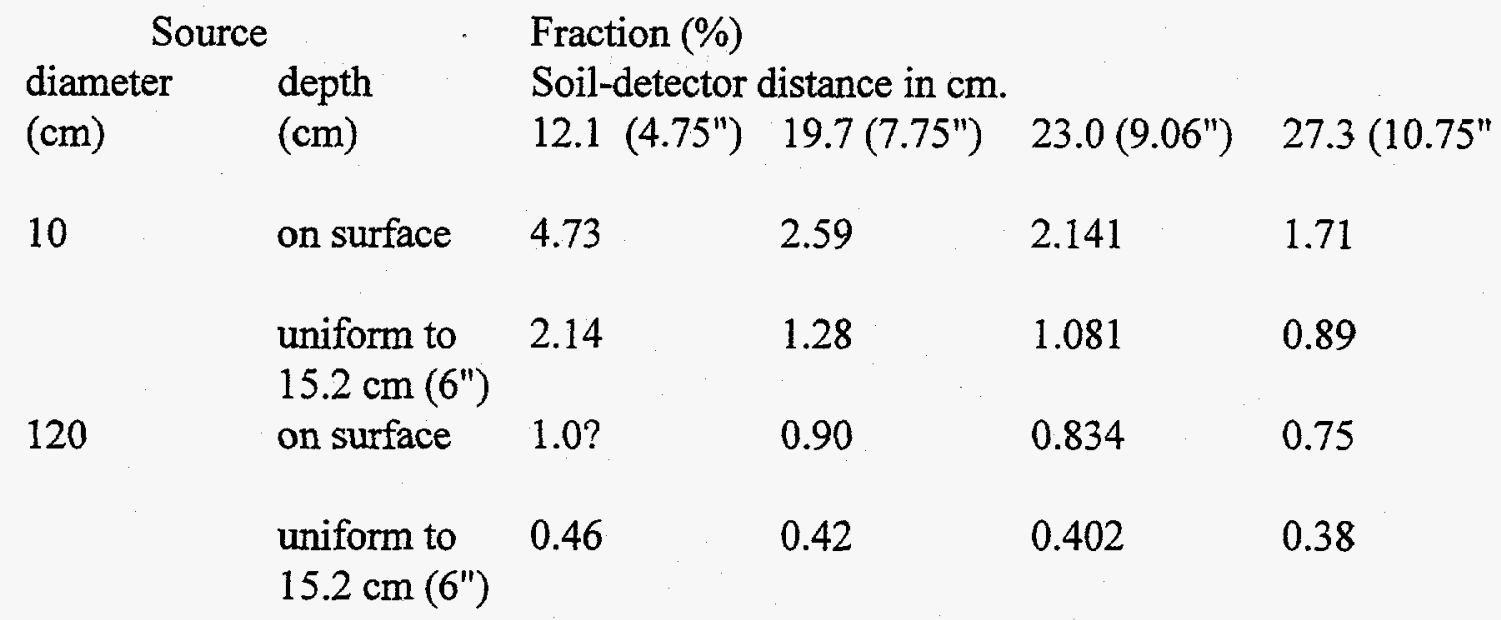

For the smaller diameter sources, this fraction simply decreases with the solid angle subtended by the detector as viewed from the soil. For the larger diameter the change with distance is much smaller because the detector views more of the source as it is raised above the ground.

B. The Ge detector

A large number of CYLTRAN runs have been made to explore a variety of measurement parameters for in situ counting with the Ge detector. This detector had been mounted inside a shield which extended about $2.75^{\prime \prime}$ beyond the detector housing and usually the shield is 6 " from the soil. The modeling was done for the following variables: diameter of source on soil surface, depth of a disk source in the soil, and composition and density of soil. The conclusions from some of these modeling calculations follow.

\section{Source-Detector Distance}

For measurements in the field, it will often be difficult to control the source-detector distance. Therefore, it is desirable to know the influence of the source-detector distance on the count rate. Calculations of the peak efficiency, $G_{p}$, at $660 \mathrm{keV}$ were made for two distances and two source diameters for a source on the soil surface.

Table B-2

$\begin{array}{clc}\begin{array}{c}\text { Source-detector } \\ \text { distance }(\mathrm{cm})\end{array} & \begin{array}{l}\text { Relative peak count rate } \\ \text { Point } \\ \text { source }\end{array} & \begin{array}{l}\text { 60-cm diameter } \\ \text { source }\end{array} \\ 15.2\left(6^{\prime \prime}\right) & 2.05 & 1.04(3) \\ 22\left(8.66^{\prime \prime}\right) & / 1.00 & / 1.00\end{array}$


For the point source, the change is simply the result in the change in the solid angle subtended by the detector from the source point, that is, $(22.0 / 15.2)^{2}$. In contrast, for the large source as the distance in increased, the decrease in solid angle is compensated for by the fact that the detector sees a larger source area.

An interesting conclusion from these data is that for field surveys changes in the source-detector distance are not important for the determination of the source activity level for large area sources.

\section{Influence of Depth in Soil}

If the source is distributed down into the soil, there are three factors that influence the observed count rate. For a given specific activity of the source, as the depth increases (1) the distance to the detector increases, so the count rate decreases; (2) the detector views a larger source area, so the count rate increases; and (3) the photon attenuation in the soil increases, so the count rate decreases.

As a function of the depth in the soil, the peak efficiencies (or counts) were computed for 660$\mathrm{keV}$ photons of interest for ${ }^{137} \mathrm{Cs}$ with the following results:

Table B-3

$\begin{array}{lll}\begin{array}{l}\text { Source } \\ \text { diameter } \\ (\mathrm{cm})\end{array} & \begin{array}{l}\text { Depth in } \\ \text { soil } \\ (\mathrm{cm})\end{array} & \begin{array}{l}\text { Relative peak } \\ \text { count }\end{array} \\ 60 & 0 & / 1.000 \\ & 2 & 0.82 \\ & 4 & 0.61 \\ & 8 & 0.34 \\ & 16 & 0.081\end{array}$

For photons of $660 \mathrm{keV}$, the count rate will have significant contributions down to 10 to $16 \mathrm{~cm}$ and a cover of a few $\mathrm{cm}$ of clean soil will not be a serious hindrance.

\section{Influence of Source Diameter}

For a ${ }^{137} \mathrm{Cs}$ source (i.e., $662-\mathrm{keV} \gamma$ rays) uniformly distributed on the soil surface, the peak count, or efficiency, was computed as the source diameter increased. The sources all have the same specific areal activity, or disintegrations per $\mathrm{cm}^{2}$; that is, the total source activity increased as the square of the source diameter. 
Table B-4

$\begin{array}{cl}\begin{array}{c}\text { Source diameter } \\ (\mathrm{cm})\end{array} & \begin{array}{l}\text { Relative peak } \\ \text { count }\end{array} \\ 20 & 0.342(14) \\ 30 & 0.638(19) \\ 40 & 0.93(3) \\ 52 & 0.99(3) \\ 56 & 1.00(3) \\ & \\ 60 & 0.99(2) \\ 64 & / 1.00(2) \\ 80 & 1.02(3) \\ 100 & 1.04(2) \\ 140 & 1.00(2)\end{array}$

(The large number of values for diameters of 52 to 64 is to cover the region where the shield begins to intercept the photons from the outer portion of the disk source.)

These data show that for sources larger than $40 \mathrm{~cm}$ in diameter, the photons from the outer portion of the source are blocked by the shield.

\section{Influence of Soil Composition and Density}

Modeling calculations were done to determine if the soil composition had any discernable influence and to verify the expected density influence. These CYLTRAN calculations were for $662-\mathrm{keV}$ photons and a $60-\mathrm{cm}$ diameter source.

Some of our early runs were done with the soil represented as simply $\mathrm{SiO}_{2}$. But, most of them were done with a Beck soil composition with a water content, by weight, of $0 \%, 10 \%$, or $20 \%$. For the $10 \%$ water content, the chemical composition of the Beck soil, by weight, is $\mathrm{SiO}_{2} 67.5 \%$, $\mathrm{Al}_{2} \mathrm{O}_{3} 13.5 \%, \mathrm{H}_{2} \mathrm{O} 10 \%, \mathrm{Fe}_{2} \mathrm{O}_{3} 4.5 \%$, and $\mathrm{CO}_{2} 4.5 \%$ which gives the elemental composition of $\mathrm{O}$ $55.8 \%$, Si $31.6 \%$, Al $7.2 \%$, Fe $3.1 \%, \mathrm{C} 1.2 \%$, and $\mathrm{H} 1.1 \%$.

For sources at depths of 4 and $8 \mathrm{~cm}$, the results are: 
Table B-5

\begin{tabular}{lllc}
$\begin{array}{l}\text { Source } \\
\text { depth }(\mathrm{cm})\end{array}$ & \multicolumn{1}{c}{$\begin{array}{c}\text { Soil } \\
\text { composition }\end{array}$} & $\left(\mathrm{g} / \mathrm{cm}^{2}\right)$ & $\begin{array}{c}\text { Density } \\
\text { count - at one depth }\end{array}$ \\
4 & $\mathrm{SiO}_{2}$ & 1.5 & 1.00 \\
& dry Beck & 1.5 & 1.00 \\
& $20 \% \mathrm{H}_{2} \mathrm{O}$ Beck & 1.5 & 0.99 \\
& & & \\
8 & $\mathrm{SiO}_{2}$ & 1.5 & 0.98 \\
& dry Beck & 1.5 & 1.03 \\
& $20 \% \mathrm{H}_{2} \mathrm{O}$ Beck & 1.5 & 0.98
\end{tabular}

The three values for each depth all agree, so these three soils are equivalent. 